\title{
Seismic risk management through insurance and its sensitivity to uncertainty in the hazard model
}

\author{
Athanasios Gkimprixis $^{1}$ (D) . John Douglas ${ }^{1}$ (ID $\cdot$ Enrico Tubaldi $^{1}$ (i)
}

Received: 23 October 2020 / Accepted: 10 April 2021 / Published online: 26 April 2021

(c) The Author(s) 2021

\begin{abstract}
Acknowledging the devastating consequences of past earthquakes, current research efforts focus on the development of tools for assessing and controlling the risk and losses associated with future earthquakes, in addition to trying to minimize construction costs. Apart from providing a control of these levels, earthquake engineering can also provide solutions to manage the financial implications of the expected hazardous events. The first part of this article focuses on the management of the expected losses through the mechanism of transfer of the financial risk via earthquake insurance. Various insurance models are explained and applied in different case studies, and numerous analyses are performed across Europe, for a benchmark four-storey reinforced-concrete frame building. The results highlight significant variation in the premiums with seismicity, design practices and properties of the insurance model. It is crucial that any mitigation or transfer framework should use probabilistic methods to consider the uncertainties inherent in the hazard and structural response estimates. For example, different studies for the same region often indicate considerable differences in seismic hazard estimates. The uncertainty inherent in the hazard input model is transferred to and affects the results of the structural design and the performance assessment. Thus, the second part of the article investigates the impact of the epistemic uncertainty in the hazard model on the structural design and consequently the estimated future losses and risk levels, again for the benchmark building. First, a comparison is performed between the hazard data from two studies for different locations in Italy, in order to assess the possible range of variation in estimated hazard levels amongst different studies. The effects of these hazard variations on the seismic design and risk and loss metrics for the benchmark building are also investigated for these locations. Finally, a simplified approach for modelling hazard uncertainty is introduced and various sensitivity analyses are performed to investigate the effects of the hazard uncertainty across Europe. It is shown that hazard uncertainty can be of differing importance for the various involved stakeholders.
\end{abstract}

Keywords Seismic risk management · Hazard uncertainty · Earthquake insurance premium $\cdot$ Reinforced concrete buildings $\cdot$ Financial loss $\cdot$ Uniform hazard

Athanasios Gkimprixis

agkimprixis@gmail.com

1 Department of Civil and Environmental Engineering, University of Strathclyde, Glasgow, UK 


\section{Introduction}

Two mechanisms are usually employed to manage the implications of earthquakes: mitigation and transfer (Goda et al. 2014). The first mechanism aims to reduce the risk levels a structure or facility is exposed to and thus mitigate the losses, in addition to increasing the safety levels. This can be achieved, for example, by developing and enforcing seismic provisions in national regulations for the design of new buildings. Improving seismic design standards can sometimes be difficult, since the future benefits are more uncertain compared to the immediate costs involved. It is often achievable, however (Olshansky 2005). Moreover, attempts have been made at the national level to promote strengthening strategies by providing tax deductions for such improvements, for instance in Berkeley, USA (Spence 2007), or more recently in Italy with the Sismabonus project (Cosenza et al. 2018).

In the transfer mechanism, a percentage of the losses is covered by a third party (e.g. an insurance or re-insurance company). Usually, it is agreed that the homeowners will still have to cover losses from small events that happen frequently, but they will transfer the responsibility of dealing with the effect of more catastrophic events to the insurer. It is surprising though that even in seismically active areas earthquake insurance is not very widespread. For example, in California fewer than $20 \%$ of the residential buildings are insured (Spence 2007). As explained by Kunreuther (1993), one reason is that homeowners either question the benefits compared to the insurance cost or they feel that a disaster will not happen to them. A survey by Palm (1995) showed that a person's response to earthquake hazard can be affected by various parameters, such as equity, income, age, gender, proximity to risk-prone areas, and experience from past events. Insurance companies can also be reluctant to promote this type of insurance, fearing the uncertainty of major earthquakes, which can be devastating for the economic survival of the company. This reluctance is usually overcome by reinsurance, which aims to transfer the risk of a very large loss from (often national) insurance companies to (international) reinsurance companies.

It is also interesting that earthquake insurance penetration rates (i.e. percentage of global insurance premiums over a country's gross domestic product) are unevenly distributed among different countries. Apart from the differences in the seismicity and exposure levels of the various regions, other factors can explain this heterogeneity, e.g. societal (income, educational level, and available information that can influence public willingness to insure) and political (government involvement in the insurance sector). Globally, these rates vary from 1\% to almost 100\% (Michel 2014). Maccaferri et al. (2011) find significant variation of the penetration rates (from 5 to $90 \%$ ) in the different EU member states. It is noted that many regions of high seismicity (e.g. Greece and Italy) have very low penetration rates (below 10\%). On the other hand, high penetration rates can be seen in locations of low seismicity (e.g. the UK). This is attributed to the fact that earthquake insurance is usually bundled with other policies (e.g. insurance for fire, personal accidents, life assurance and property loss) in the countries with high penetration rates. Maccaferri et al. (2011) also highlight the importance of "risk-based" insurance, as opposed to flat pricing. They note that only six member states have risk-based insurance policies.

The evaluation of the seismic risk of a structure, a necessary input in the definition of any mitigation or transfer framework, is affected by significant uncertainties. These uncertainties are often denoted by the adjectives "aleatory" and "epistemic", and affect the three key components of seismic risk, namely the hazard, the structural vulnerability and the exposure. The definition of seismic hazard curves for a site is affected by substantial epistemic uncertainty, in addition to the randomness inherent in the occurrence of a 
major earthquake and its ground motions. This is reflected in the significant difference in the assessed seismic hazard according to different studies for the same region. For example, Belvaux et al. (2014) compared the results of two different hazard studies for France, showing that the values of the mean peak ground acceleration (PGA) for a 475-year return period from the 2013 European Seismic Hazard Model (ESHM13) (Giardini et al. 2013; Woessner et al. 2015) are on average half of those obtained by the MATE-02 project (Martin et al. 2002). Significant differences are noted also in Germany in Grünthal et al. (2014) between the results from ESHM13 and an older national hazard map. An updated PSHA for Romania was performed by Pavel et al. (2016). They observed that ESHM13 gives on average significantly lower values of PGA for a mean return period of 475 years compared to their results. This epistemic uncertainty is particularly influenced by the choice of the ground motion prediction equations used for describing the seismic attenuation from the source to the site (Grünthal et al. 2018; Douglas et al. 2014; Stucchi et al. 2011; Bradley 2009) as well as choices made in the characterization of the seismic sources (e.g. fault recurrence intervals).

This article presents an investigation of how the seismic hazard, and its uncertainty can affect risk management plans. For this purpose, the four-storey reinforced-concrete (RC) building of a previous article by the same authors of this work is considered (Gkimprixis et al. 2020), together with different seismic hazard scenarios in Europe. Section 2 illustrates a brief overview of the design and risk and loss assessment of the building, whereas Sect. 3 discusses the topic of loss-based earthquake insurance. The effect of the assumptions made for the insurance model on the resulting premium rates is first investigated. Then a procedure for defining the insurance model's properties based on a target limit for the loss coverage is suggested and applied across Europe, using the data for the aforementioned building.

The second part of the article investigates the effect of the epistemic uncertainties inherent in the definition of the seismic hazard on the design and consequently on the seismic risk estimates, the construction costs and the expected losses (i.e. the parameters that define any risk management framework) for the benchmark building. The study's results shed light on the levels of accuracy to be sought in the definition of the hazard by considering the impact of the hazard uncertainty on the building's cost and safety.

It is highlighted that an important aspect to be considered when applying a framework among different countries is data harmonization. For this reason, a harmonized (during a three-year European project with inputs from hundreds of experts) seismic hazard model for Europe (ESHM13) is used herein. Also, there is a move in Europe to define harmonized design standards through the adoption of the design criteria in the Eurocodes. Data harmonization becomes more difficult, however, when the involved construction costs are considered, since material and labour costs can differ significantly among different countries. This subject needs further investigation in the future, if further harmonization is sought.

\section{Overview of the risk and loss assessment methodology}

This section presents a brief summary of previous research by the authors (Gkimprixis et al. 2020), to demonstrate the risk and loss assessment methodology that is the basis of the work presented here. The study concerns a 4-storey 3-bay RC building (Fig. 1), designed according to Eurocodes (CEN 2004a, b) considering different levels of the design peak ground acceleration $\left(\mathrm{PGA}_{\mathrm{d}}\right.$ ), namely $0.0 \mathrm{~g}, 0.1 \mathrm{~g}, 0.3 \mathrm{~g}$ and $0.5 \mathrm{~g}$ (infills 
(a)

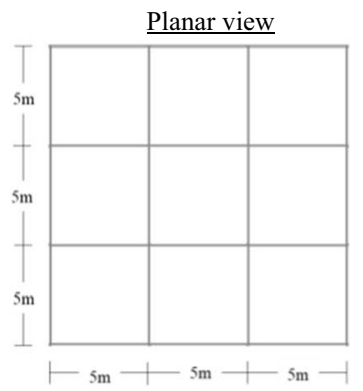

(b)

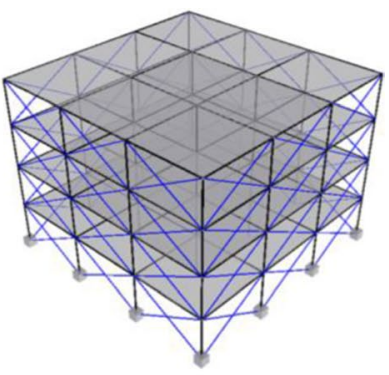

Fig. 1 Benchmark building: a geometry, and b numerical model used for nonlinear analyses

considered only in the assessment), and using the Type 1 horizontal design acceleration spectrum of Eurocode 8 (EC8) (CEN 2004b), together with the assumption of class B soil conditions.

The seismic performance of the models under increasing seismic intensity was estimated via incremental dynamic analyses (Vamvatsikos and Cornell 2002). The results of these analyses were fitted using the maximum-likelihood approach (Shinozuka et al. 2000) to derive fragility curves for every component (structural and non-structural) of each storey explicitly (76 fragility curves for each model). A lognormal distribution function was used for the analytical expression of the fragility curves, and inter-storey drift and acceleration thresholds were defined to consider different limit state conditions of the drift-sensitive and acceleration-sensitive components.

A risk analysis was then performed to evaluate the annual collapse risk of the designed models, using as a risk metric the mean annual frequency (MAF) of collapse, $\lambda_{C}$. This is obtained from the convolution of the fragility curve of the building for 'global collapse' (i.e. the building collapses if the collapse criterion is met at any storey) and the hazard curve of the assessed location, $H$ (IM). Analytically it can be expressed as (Kennedy 2011):

$$
\lambda_{C}=\int P(C \mid \mathrm{IM}) \cdot|d H(\mathrm{IM})|
$$

where $|d H(\mathrm{IM})|$ denotes the absolute value of $d H(\mathrm{IM})$, with $d$ being the differential operator. The hazard curve provides the MAF of exceeding various levels of the seismic intensity measure (IM), whereas the fragility, $P(C \mid \mathrm{IM})$, refers to the probability of collapse conditional on the IM level.

The construction costs for the four $\mathrm{PGA}_{\mathrm{d}}$ levels and a damage and loss model were used to convert the fragility curves to vulnerability curves, expressing the expected value of annual losses conditional on the IM, $E[\mathrm{AL} \mid \mathrm{IM}]$. The total vulnerability of the building equals the sum of the vulnerability of each component at every storey, which is based on the fragility curves of the component for the various damage states and the costs associated with each damage state. The inputs and approach for loss assessment were based on various studies (e.g. Wen and Kang 2001; Lagaros 2007; Kappos and Dimitrakopoulos 2008; Padgett et al. 2010; Crowley et al. 2012; Ramirez et al. 2012; Ordaz et al. 2017). The losses derived from the cost of repairing/replacing the damaged structure. In addition to these, additional losses (e.g. from personal property damage, injuries or fatalities, and loss of function of the building) were also considered. 
Following Ramirez et al. (2012), the collapse (C) and no-collapse (NC) cases are considered separately in the loss assessment, according to the following expression:

$$
E[\mathrm{AL} \mid \mathrm{IM}]=E[\mathrm{AL} \mid \mathrm{NC}, \mathrm{IM}] \cdot[1-P(C \mid \mathrm{IM})]+C_{r} \cdot P(C \mid \mathrm{IM})
$$

where $C_{r}$ is the cost associated with the case of collapse. If the collapse criterion is met at any storey, then it is assumed that the whole building has collapsed ('global collapse' case), and consequently it has to be replaced.

The convolution of the vulnerability, $E[\mathrm{AL} \mid \mathrm{IM}]$, with the hazard gives the expected annual losses, $E A L$, as:

$$
E A L=\int E[\mathrm{AL} \mid \mathrm{IM}] \cdot d H(\mathrm{IM})
$$

The expected cost due to the future losses over a time period $t$ is calculated as:

$$
E[\mathrm{FL}]=\mathrm{EAL} \cdot\left(1-e^{-r_{d} \cdot t}\right) / r_{d}
$$

where $r_{d}$ is a constant discount rate/year, which converts the future losses into present monetary value.

Finally, the expected value of the life-cycle cost, $E[\mathrm{LCC}]$, over the time period $t$, can be expressed as:

$$
E[\mathrm{LCC}]=C_{0}+E[\mathrm{FL}]
$$

where $C_{0}$ is the initial construction cost and $E[\mathrm{FL}]$ is the expected cost due to future losses.

Focusing on the risk mitigation mechanism, the previous work (Gkimprixis et al. 2020) investigated three alternative seismic design approaches. According to the uniform hazard approach, which is the basis of most design regulations, the design acceleration is chosen as the value that has a predefined probability of exceedance in a given time period (e.g. $10 \%$ in 50 years). This simplifying approach was compared to two more advanced and rigorous methods that aim to control the risk and loss levels at the design stage. In the following section, this approach and the results of the study described in this section are used to investigate possible strategies for seismic loss management through the transfer mechanism. In the final section, the problem of uncertainty in the hazard is discussed and various sensitivity analyses are performed to highlight its importance when defining a risk mitigation or transfer plan.

\section{Insurance strategies for seismic loss management}

A typical insurance strategy involves the definition of two quantities, namely the deductible $(D)$ and the limit $(L)$, denoting respectively the minimum and maximum losses covered by insurance in the case of an incident/hazardous event (Goda et al. 2014). Assuming that all the losses between $D$ and $L$ are covered by the insurer (i.e. there is no coinsurance), the total amount covered (claim) is obtained as (Goda et al. 2014):

$$
\text { claim }= \begin{cases}0, & \text { for loss } \leq D \\ \operatorname{loss}-D, & \text { for } D<\operatorname{loss}<L \\ L-D, & \text { for loss } \geq L\end{cases}
$$


The claim sets the minimum (or pure) premium that the company should charge to cover the expected losses. Obviously, the insurance premium must be increased for the company to make a profit. The insurance premium can be expressed as (Yucemen 2013):

$$
\text { insurance premium }=\text { claim } /(1-L F)
$$

where LF is a load factor introducing hidden uncertainties, other expenses and the profit of the insurer. The minimum insurance premium that the company should charge just to cover the expected costs/expenses and have no profit is obtained by setting $L F=0$, and is equal to the homeowner's claim. The premium would need to be increased by assuming a higher LF value for the company to make a profit. For example, Yuceman (2013) reports for Turkey that LF equals 0.4 , which translates into an increase of $67 \%$ over the minimum premium.

With the deductible the insurance company avoids dealing with small claims that can happen more often and that can be covered directly by the owner. The aim of the limit point is to protect the insurance company from extreme scenarios that can jeopardize the economic survival of the company. These points are defined based on the needs of the involved stakeholders (e.g. property owners, insurance and reinsurance companies, capital market and government). In a typical insurance scheme, $D=10 \%$ and $L=50 \%$ of the insured value (Yoshikawa and Goda 2014), though different schemes can be defined. A review of the existing insurance systems applied in various countries by Goda et al. (2014) shows that deductible values between 1 and $15 \%$ are usual. Other techniques to define the deductible and limit points can be found in the literature, for example based on the return period (Pakdel-Lahiji et al. 2015).

As an example, Fig. 2a shows the insurance model for $D$ and $L$ set to $10 \%$ and $50 \%$ of the construction cost, respectively. With this model, the owner cannot claim anything if the losses are less than $10 \%$ of the construction cost, while for more extensive damage the company will pay the difference, with a maximum coverage of $50 \%-10 \%=40 \%$ of the building's value. The extreme case of full insurance $(D=0, L=100 \%$ of the construction cost) is given as well, which means that all losses are covered by the insurance company. Also, a second example for the partial insurance model is shown in Fig. 2b, with $D$ and $L$ assumed equal to $2 \%$ and $25 \%$, respectively. These models are implemented in the case studies of the following section. It is clarified that the construction cost herein refers to the

(a)

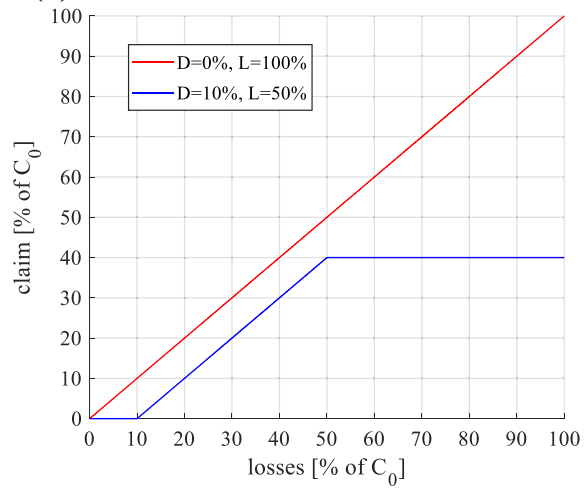

(b)

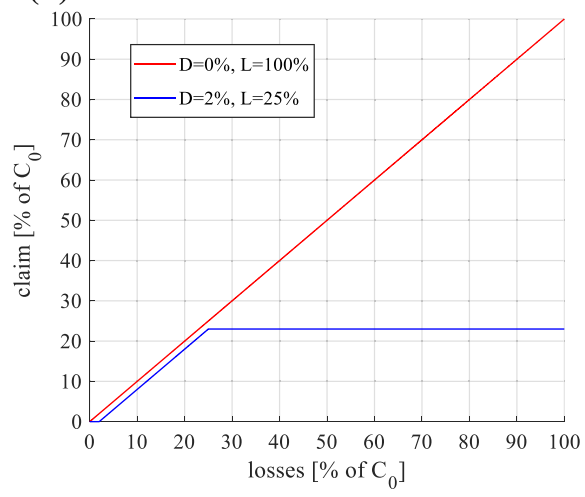

Fig. 2 Claim for the case of full insurance (claim=losses), and partial insurance with: a $D=10 \%, L=50 \%$, and b $D=2 \%, L=25 \%$ 
cost of structural and non-structural components only. No additional losses are included (e.g. due to personal contents loss, income and rental losses or injuries and fatalities) since they can be considered separately with different insurance models.

\subsection{Application of the insurance models}

This section presents an application of earthquake insurance modelling for the 4-storey 3-bay RC building which was designed (using the uniform-hazard approach) and analysed in Gkimprixis et al. (2020) (see Sect. 2). In this example, the building is located in Aigio, Greece $\left(38.2^{\circ} \mathrm{N}-22.082^{\circ} \mathrm{E}\right)$. First, the hazard curve for the location is obtained from ESHM13 (Giardini et al. 2013; Woessner et al. 2015). Then, the acceleration level, PGA $^{\mathrm{UH}}$ corresponding to a MAF of exceedance equal to $1 / 475$ (10\%-in-50-years probability of exceedance) is obtained from the hazard curve (see Fig. 5 ). Using this value $(0.48 \mathrm{~g})$ as the design acceleration, the corresponding vulnerability curve is derived based on the results of Gkimprixis et al. (2020). In that work, site class B was assumed in the seismic design stage. Therefore, the hazard curve of the location is multiplied by the soil factor 1.2 (expressing the ratio between PGAs on site classes B and A in EC8) to consider class B soil conditions. With this hazard curve and the vulnerability curve of the designed building, the loss exceedance curve (red curve) of Fig. 3 is derived. In particular, the losses and the MAF are equal to the $E[\mathrm{AL} \mid \mathrm{IM}]$ calculated with Eq. (2) and the corresponding $H(\mathrm{IM})$, respectively. This curve gives the MAF of exceeding different levels of losses and the area under the curve gives the EAL. In this example, the EALs (accounting for repair costs only) are equal to $1,584 €$.

In the case of a fully insured building, these losses would all be covered by the insurance company (claim $=\mathrm{EAL})$. If the partial insurance model of Fig. $2 \mathrm{a}(D=10 \%, L=50 \%)$ is applied instead, a new curve is derived (black curve) for the owner, which shows the percentage of the losses that can be claimed. This can be obtained by evaluating, for each loss level, the portion of costs covered by the owner and those covered by the insurer. The owner has to cover the losses that are under the black curve, while the rest are covered by the insurance contract and thus transferred to the insurance company. In other words,

(a)

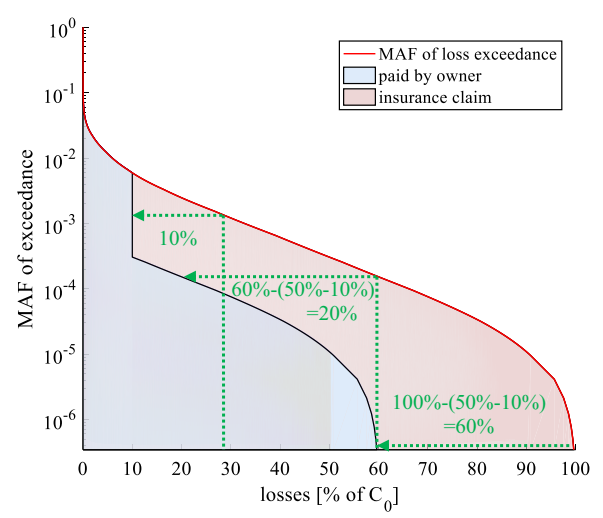

(b)

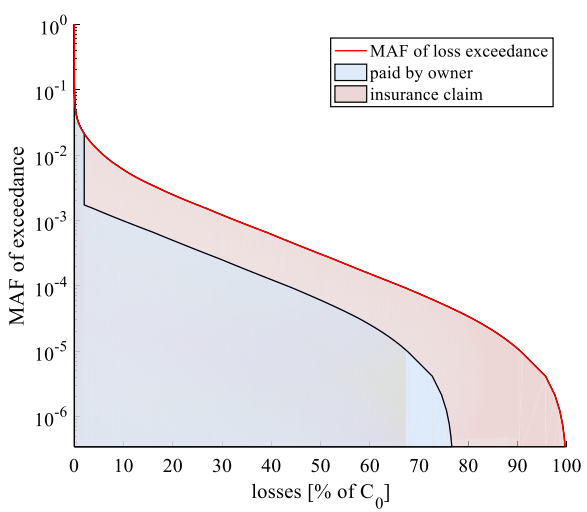

Fig. 3 Loss exceedance curve for Aigio together with the part that is covered by partial insurance, assuming: a $D=10 \%, L=50 \%$, and $\mathbf{b} D=2 \%$ and $L=25 \%$ 
from the $1,584 €$ mentioned above, $478 €$ are covered by the insurance and the remaining repair costs $(1,106 €)$ would need to be covered by the homeowner alone. Thus $478 €$ is the minimum amount that the company should charge to cover their expenses, i.e. insurance premium $=$ claim, assuming $\mathrm{LF}=0$ in Eq. (7).

Given that only $30 \%$ of the EAL (i.e. $478 €$ of 1,584€) are covered in this example, a different insurance scheme is investigated, by implementing the model of Fig. $2 \mathrm{~b}(D=2 \%$, $L=25 \%$ ) and the results are presented in Fig. 3b. With these parameters, $60 \%$ of the losses ( $945 €$ ) would be covered by the insurer, leaving the homeowner to deal with the remaining EAL (639€). It is obvious from Fig. 3 that the amount of $1,584 €$ considers the whole range of potential losses together with their MAF of exceedance. In order to understand which levels of losses contribute most to the total EAL, a disaggregation of the $1,584 €$ in terms of the different levels of the incurred losses is presented in Fig. 4. The horizontal axis in that figure is $E[\mathrm{AL} \mid \mathrm{IM}]$, and the vertical is the corresponding percentage of the EAL (i.e. of $1,584 €$ in this example). Almost $50 \%$ of the EAL is derived from losses that are smaller than $5 \%$ of the initial cost, which have high MAF of exceedance (Fig. 3), while the contribution of losses higher than $30 \%$ is negligible. A sensitivity analysis of the claim with regard to the values of $D$ and $L$ is also presented in the same figure. As stated before, the typical assumption of $D=10 \%$ and $L=50 \%$ gives a $30 \%$ coverage of the EAL by the insurance, i.e. the owner has to manage the remaining $70 \%$.

Similar observations were made by other researchers. Yucemen (2013), for example, mentions that the very small deductible ( $2 \%$ in contrast to the more usual value of $10 \%$ ) suggested by the current insurance policy in Turkey leads to increased premium rates. This is because the small to moderate earthquake events that cause small losses but happen more frequently contribute more to the EAL. For example, earthquakes causing macroseismic intensity VI (corresponding to slight damage) can contribute from 29 to $64 \%$ to the EAL, depending on the location considered. By ignoring the contribution of macroseismic intensity $\mathrm{V}$ events (to account for the deductible point), the 'pure risk premium rates' (equal to an 'expected annual damage ratio' times the 'insured value of the building') were found between 0.082 and $0.313 \%$, of the replacement cost, for RC buildings that comply with the seismic regulation, and increased to $0.155 \%$ and $0.85 \%$ for the case of no seismic provisions. Another study for the insurance modelling of residential buildings in Turkey

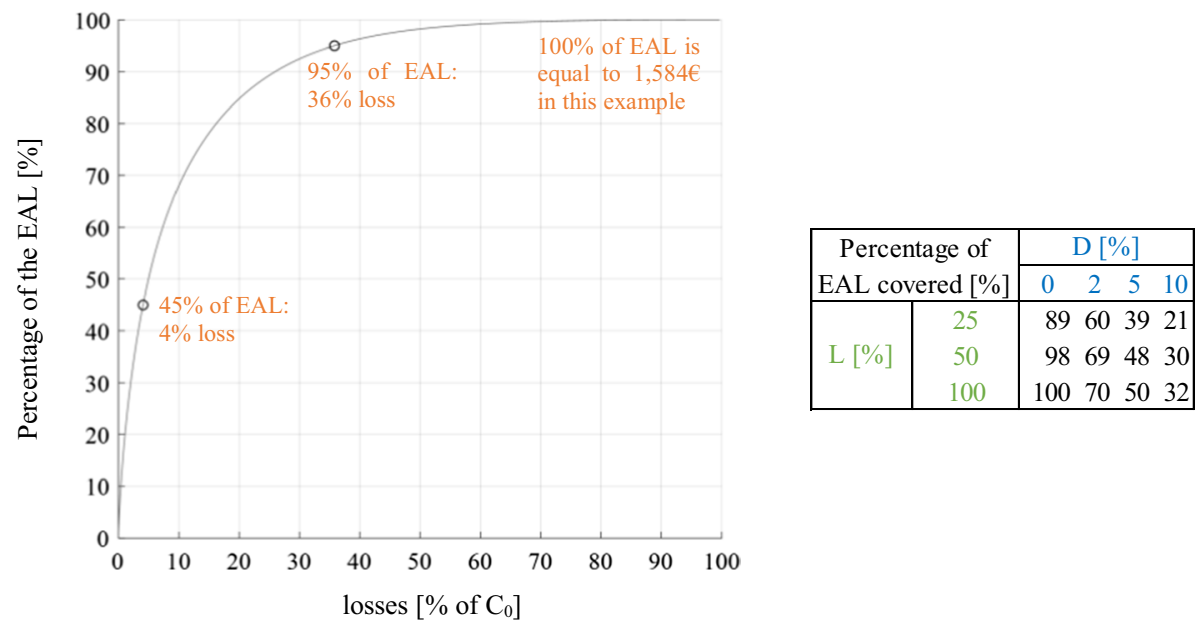

Fig. 4 Disaggregation of the EAL and their coverage for characteristic $D$ and $L$ values 
(Bommer et al. 2002) suggested values of EAL less than $0.2 \%$ of the construction cost. Motamed et al. (2019) estimated EAL for residential buildings in Iran between 0.12 and $0.5 \%$ of the replacement cost. The review of the international insurance systems of Goda et al. (2014) showed that the premium rates can vary from $0.018 \%$ to $0.9 \%$ of the construction cost, while Yucemen (2013) gave values of $0.525 \%$ for California, $0.43 \%$ for Japan and $0.727 \%$ for Mexico.

From the above it is clear that different insurance models can be defined based on national guidelines and other research works. However, as mentioned in the introduction, many homeowners are reluctant to buy earthquake insurance, as they are sceptical about the benefits compared to the premium (insurance cost). Various approaches can be proposed to help overcome this reluctance. Herein, a way to define $D$ and $L$ with the objective of sharing the EAL evenly between the insurer and the owner is investigated. Of course, this can be accomplished with many different combinations of $D$ and $L$, but the aim here is to have a deductible between 2 and $5 \%$ of the initial cost. Therefore, we consider it more reasonable to set $D$ and $L$ as the points where $45 \%$ and $95 \%$ of the EAL are concentrated. This will result in the owner covering the $45 \%$ of EAL that come from small earthquake events and $5 \%$ of the losses that come from very rare events, leaving the remaining $50 \%$ (from 45 to $95 \%$ ) to the insurer. Other $D$ and $L$ values could also be considered, but this is outside the goal of this study. If this scheme is applied in the case study, the deductible and limit points are $D=4 \%$ and $L=36 \%$ (see Fig. 4).

\subsection{Investigation for Europe}

This subsection investigates the sensitivity of the percentage of the EAL that is transferred to the insurer, on the assumptions made for the deductible and limit points, considering various sites in Europe characterized by different seismicity. In Europe, there is a strong variation in the hazard from site to site, with changes not only in the PGA levels for the design return period, but also in the shape of the hazard curve. This obviously affects the risk estimates and the losses expected to be incurred. Figure 5a shows the selected locations across Europe, together with the uniform hazard PGA with a return period of 475 years, PGA ${ }^{\mathrm{UH}}$, obtained from ESHM13 (Giardini et al. 2013; Woessner et al. 2015). The hazard curves of the selected locations are plotted in Fig. 5b.

First, the vulnerability of the structure is estimated, based on the design acceleration, considered equal to the $\mathrm{PGA}^{\mathrm{UH}}$ for a 475 -year return period. Then, the EAL are calculated by convolving the vulnerability and hazard curves. The results expressed as a percentage of the initial construction cost are presented in Table 1. It is observed that the EAL are increased in regions of higher seismicity, even though the design acceleration is also increased (higher design requirements). A second case is also examined, which refers to buildings with no seismic provision $\left(\mathrm{PGA}_{\mathrm{d}}=0\right)$, designed only with the gravity loads combination (i.e. $1.35 \mathrm{G}+1.5 \mathrm{Q}$, where $\mathrm{G}$ and $\mathrm{Q}$ are the permanent and live loads, respectively).

Using the partial insurance model of Fig. $2 \mathrm{a}(D=10 \%, L=50 \%)$ and the procedure explained in the previous subsection, the claim values are estimated for each location. It is recalled that this parameter shows the percentage of the EAL that is covered by insurance, based on the insurance model applied. The results of Table 1 for the five locations show that the EAL covered by the insurance are small, and vary roughly between 20 and $40 \%$. If the deductible and limit points change to $2 \%$ and $25 \%$, respectively, then the percentage of the EAL that is covered by the insurance is increased, and is found in the range between 55 and $65 \%$. 
(a)

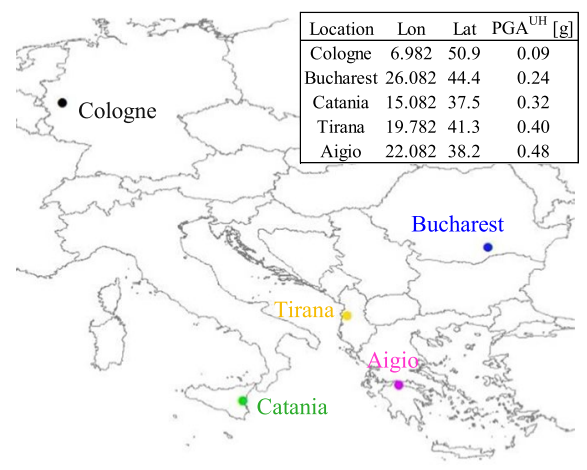

(b)

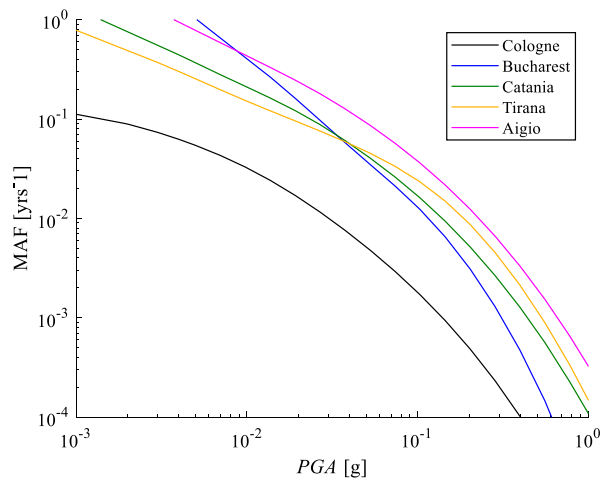

Fig. 5 Case study for Europe: a selected locations and b hazard curves (site class A)

Table 1 Investigation for five locations in Europe, for two design cases ( $\mathrm{PGA}_{\mathrm{d}}$ equal to $\mathrm{PGA}{ }^{\mathrm{UH}}$ or 0 )

\begin{tabular}{|c|c|c|c|c|c|c|c|}
\hline \multirow[t]{2}{*}{ Location } & \multirow{2}{*}{$\begin{array}{l}\text { PGA }_{d} \\
{[\mathrm{~g}]}\end{array}$} & \multirow{2}{*}{$\begin{array}{l}C_{0} \\
{[€]}\end{array}$} & \multirow[t]{2}{*}{ EAL $\left[\%\right.$ of $\left.C_{0}\right]$} & \multicolumn{2}{|c|}{ claim [\% of EAL] } & \multirow{2}{*}{$\begin{array}{l}D \text { for } 45 \% \\
\text { of EAL } \\
{\left[\% \text { of } C_{0}\right]}\end{array}$} & \multirow{2}{*}{$\begin{array}{l}L \text { for } 95 \% \text { of } \mathrm{EAL} \\
{\left[\% \text { of } \mathrm{C}_{0}\right]}\end{array}$} \\
\hline & & & & $\begin{array}{l}D=10 \% \\
L=50 \%\end{array}$ & $\begin{array}{l}D=2 \% \\
L=25 \%\end{array}$ & & \\
\hline \multirow[t]{2}{*}{ Cologne } & 0.09 & 656,691 & 0.03 & 26 & 57 & 3.19 & 30.02 \\
\hline & 0 & 655,840 & 0.04 & 27 & 56 & 3.39 & 34.18 \\
\hline \multirow[t]{2}{*}{ Bucharest } & 0.24 & 669,255 & 0.12 & 22 & 61 & 3.02 & 23.43 \\
\hline & 0 & 655,840 & 0.27 & 23 & 56 & 2.78 & 27.59 \\
\hline \multirow[t]{2}{*}{ Catania } & 0.32 & 676,639 & 0.14 & 32 & 63 & 4.53 & 34.80 \\
\hline & 0 & 655,840 & 0.36 & 32 & 58 & 4.39 & 40.04 \\
\hline \multirow[t]{2}{*}{ Tirana } & 0.40 & 684,130 & 0.18 & 31 & 64 & 4.52 & 32.89 \\
\hline & 0 & 655,840 & 0.50 & 39 & 64 & 6.17 & 41.87 \\
\hline \multirow[t]{2}{*}{ Aigio } & 0.48 & 691,820 & 0.23 & 30 & 60 & 4.08 & 35.78 \\
\hline & 0 & 655,840 & 0.82 & 34 & 59 & 4.96 & 43.06 \\
\hline
\end{tabular}

These results were expected, based on the conclusions of the previous subsection. In the previous section, we also discussed the possibility of defining $D$ and $L$ as the points where $45 \%$ and $95 \%$ of the total EAL are concentrated. Using this approach for the assessed locations herein, $D$ is found roughly between 3 and $5 \%$ and $L$ between 20 and $45 \%$ of the initial construction cost.

In order to repeat the procedure for every location across Europe, the PGA values that correspond to 1\%-, 2\%-, 5\%-, 10\%-, 39\%- and 50\%-in-50-years exceedance probabilities for the different locations are obtained from the ESHM13 project. The second-order polynomial function in log-space proposed by Vamvatsikos (2013) is used to extrapolate the hazard curves to a wider range of PGA, if required. Figure 6 presents the $\mathrm{PGA}^{\mathrm{UH}}$ values for site class A that correspond to a 10\%-in-50-years exceedance probability (MAF of exceedance $2.1 \cdot 10^{-3}$ ). As the seismic designs of the case study buildings were undertaken in Gkimprixis et al. (2020) using the EC8 spectrum for site class B, the PGAs for site class A 

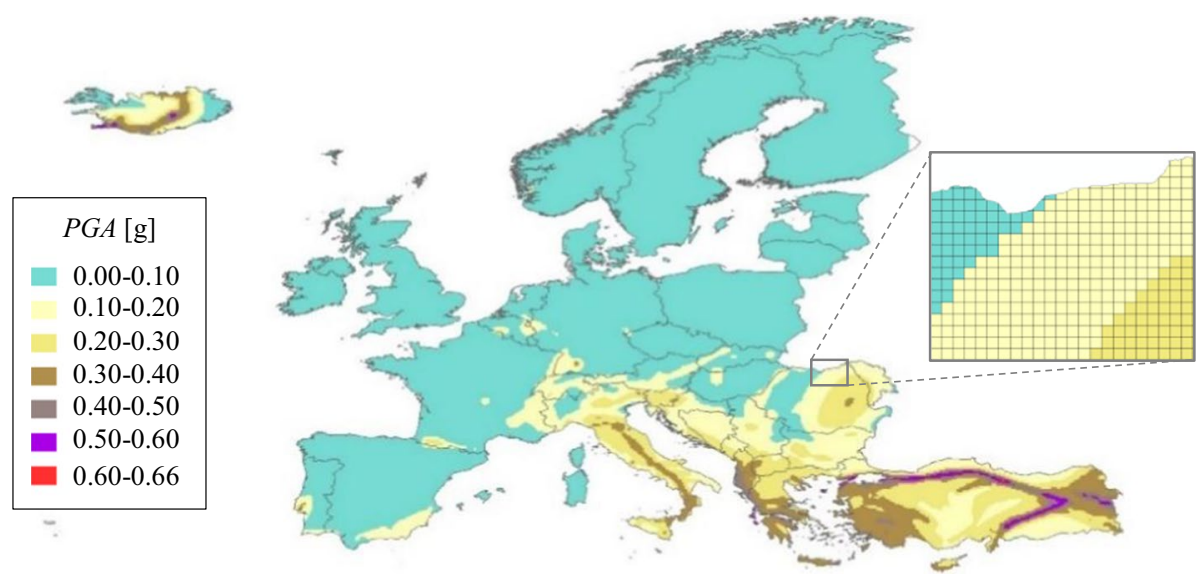

Fig. $6 \mathrm{PGA}^{\mathrm{UH}}$ values across Europe (site class A) with a 10\%-in-50-years exceedance probability

from the ESHM13 are multiplied by the soil factor 1.2, expressing the ratio between PGAs on site classes B and A in EC8, to construct the 'reference' hazard curves.

For each location the EAL are calculated based on the design PGA. The insurance premium is set equal to the EAL (case of full insurance) to calculate the minimum amount (no profit) the company should charge just to cover the expenses for the repair/replacement costs. In other words, LF in Eq. (7) is taken equal to zero. Two cases are considered: one for buildings designed with the uniform hazard approach consistent with the seismic provisions (Fig. 7a), and one for buildings designed for gravity loads only (Fig. 7b).

The maximum value of the EAL for the case of seismically designed buildings is around $2,455 €$, which increases to $11,566 €$ in the case of no seismic provision, which are equal to $0.35 \%$ and $1.8 \%$ of the construction costs of these buildings, respectively. These values are the expenses of the insurance company in the case of full insurance ( $D=0, L=100 \%)$ and can be seen as the minimum premium (no profit) for full insurance the company has to charge.

The results from the various maps can be summarized in one graph, as shown in Fig. 8, where each point refers to one specific location in Europe. In particular, the ordinate of each point gives the EAL obtained from Fig. 7a, while the abscissa gives the PGA ${ }^{\mathrm{UH}}$ associated with that location, obtained from Fig. 6. This plot helps to present the results in a clearer and more concise way than the various associated maps.

Next, the impact of the deductible and limit points on the EAL coverage is investigated, firstly for the case where seismic provisions are considered. For each location the EAL are assessed based on the hazard of the location, and the claim is defined for three insurance models: (a) full insurance ( $D=0, L=100 \%$ ), (b) $D=10 \%$ and $L=50 \%$, and (c) $D=2 \%$ and $L=25 \%$. The assessed claims for every considered location across Europe with respect to the $\mathrm{PGA}^{\mathrm{UH}}$ of the location (Fig. 6) are shown in Fig. 9a. In the case of full insurance, the claim is equal to the EAL and as stated above, a maximum value of $0.35 \%$ of the construction cost is obtained in this case. For the insurance models b and c, the maximum claim is found to be $0.10 \%$ and $0.19 \%$ of the initial construction cost, respectively.

Figure $9 \mathrm{~b}$ shows the percentage of the EAL covered by the insurance company when the other two models are applied instead of full insurance. Each point on these graphs shows the value obtained for a given location across Europe with respect to the $\mathrm{PGA}^{\mathrm{UH}}$ of this 
(a)
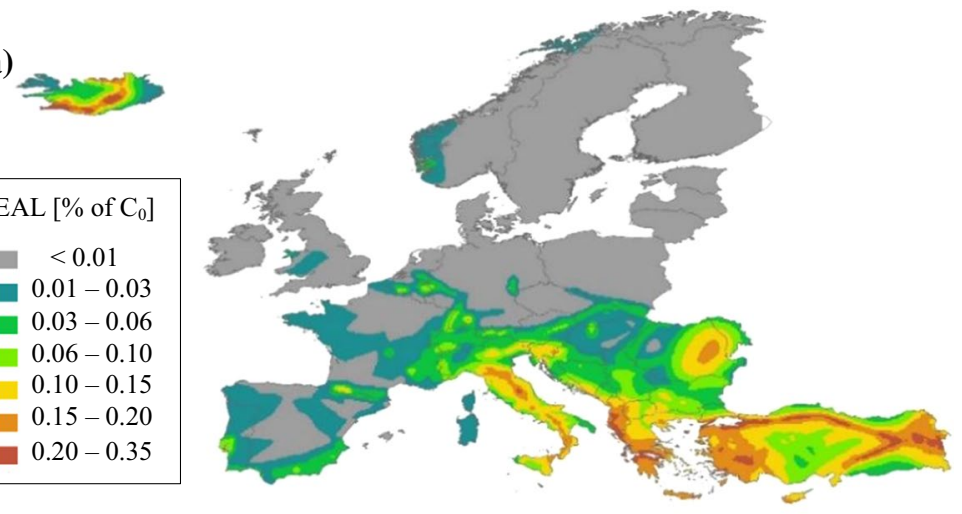

(b)

EAL $\left[\%\right.$ of $\left.\mathrm{C}_{0}\right]$

- $<0.01$

$0.01-0.03$

$0.03-0.06$

$0.06-0.10$

$0.10-0.15$

$0.15-0.20$

$0.20-0.35$
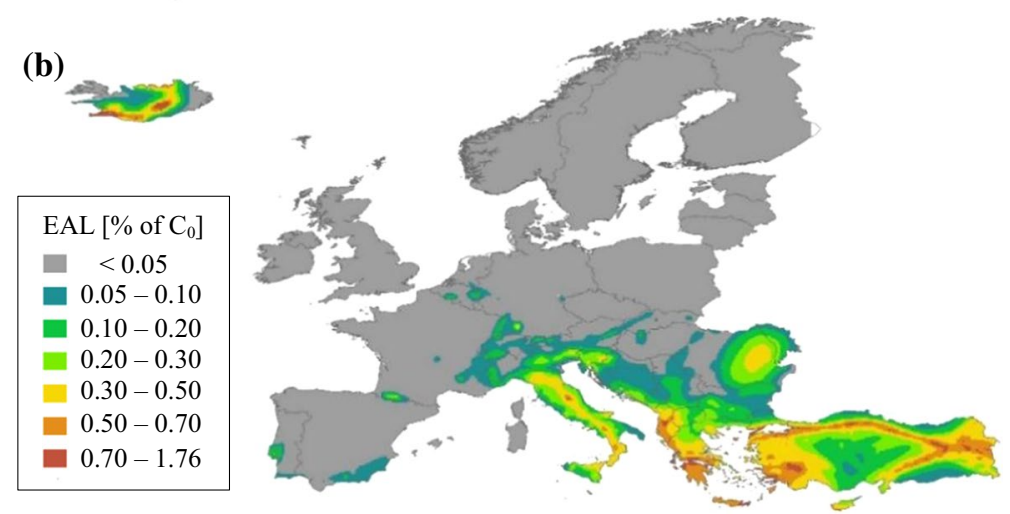

Fig. 7 Minimum premium (\% of construction cost) for full insurance when the building is designed considering gravity loads and a seismic provisions, and $\mathbf{b}$ no seismic provisions (notice the difference in the scales)

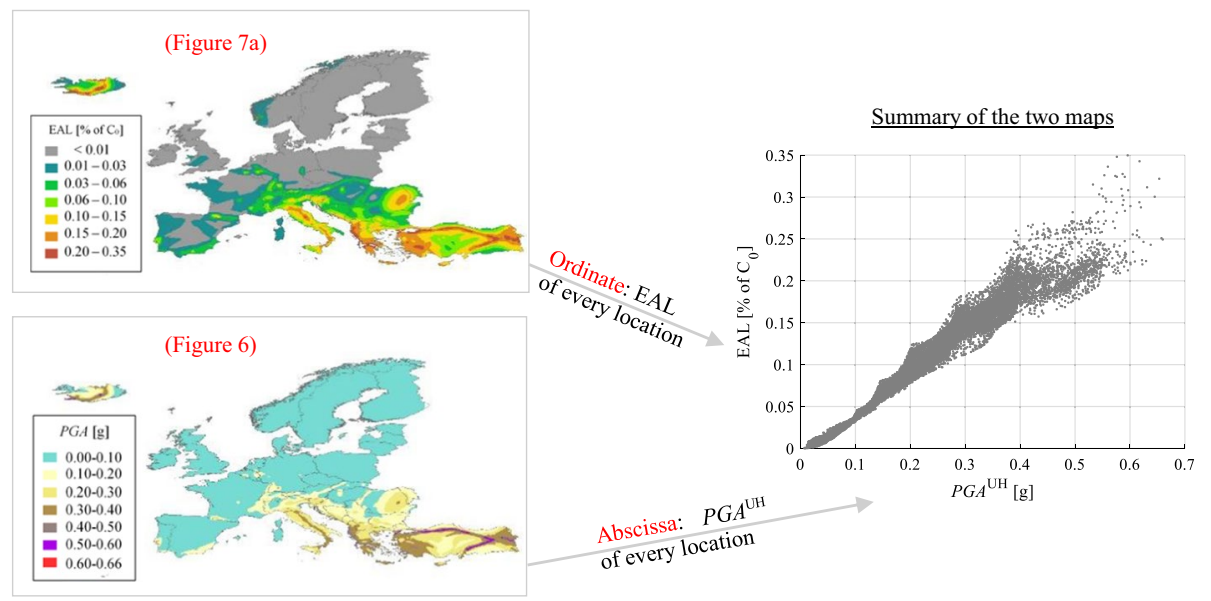

Fig. 8 Explanation of the graphs presented in the following case studies; example of summarizing the EAL calculated across the various locations 
(a)

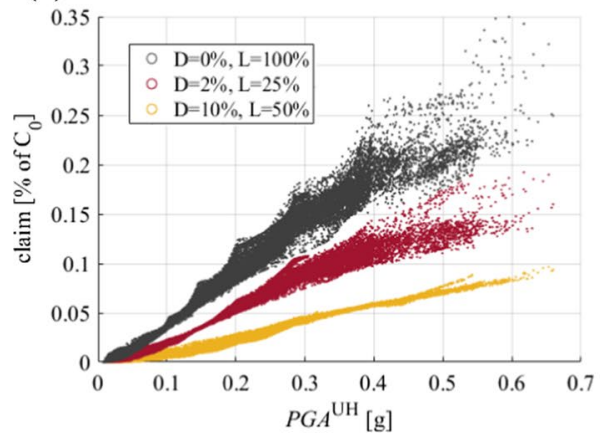

(b)

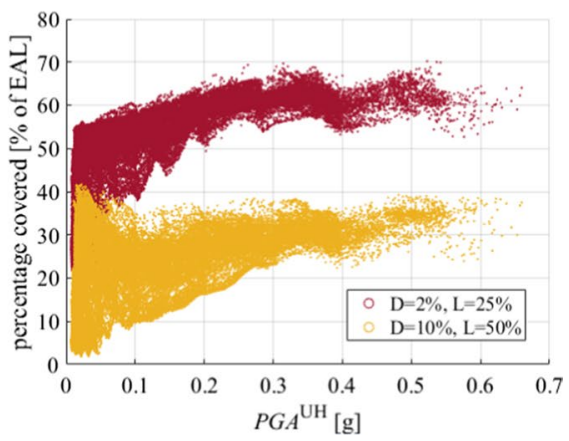

Fig. 9 Impact of the insurance model throughout Europe on a the minimum premium (for the insurance company to breakeven), and $\mathbf{b}$ the percentage of the EAL covered by insurance

(a)

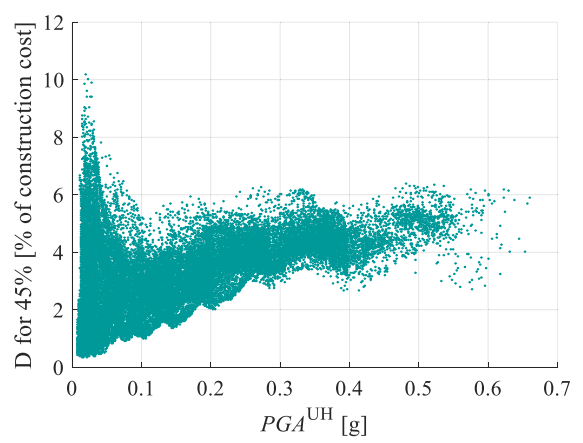

(b)

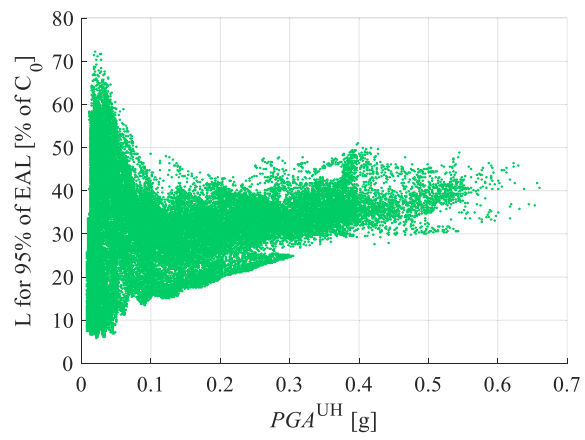

Fig. 10 Points where the a $45 \%$ and b $95 \%$ of the EAL is concentrated

location (Fig. 6). In general, it is observed that by applying model b, this percentage varies from 2 to $42 \%$ and for the model c from 19 to $70 \%$. It can be concluded that for high seismicity regions the coverage is higher than $20 \%$ and $50 \%$ when model $\mathrm{b}$ and model $\mathrm{c}$ are applied, respectively.

In order for the coverage to equal 50\% (equal share between insurance company and building owner) in every location, a disaggregation of the EAL is performed. The points where $45 \%$ and $95 \%$ of the EAL are concentrated are plotted in Fig. 10a, b, respectively. If these values are used for the $D$ and $L$, respectively, then half of the EAL are transferred to the insurance company. A further increase of the obtained $L$ values in each location does not affect the minimum premium by more than $5 \%$, though it would expose the insurer to higher financial risk.

As explained above, for low PGA values the gravity loads are most critical for the design and this leads to over-designing in some cases. This results in a high dispersion of the results in the vicinity of $\mathrm{PGA}^{\mathrm{UH}}=0$. Nevertheless, the losses in this area are quite small (see Fig. 7a). In general, it can be concluded that values roughly between 2 and $6 \%$ for the deductible are more reasonable in high seismicity regions, whereas $L$ can be set between 20 and $50 \%$. 
(a)

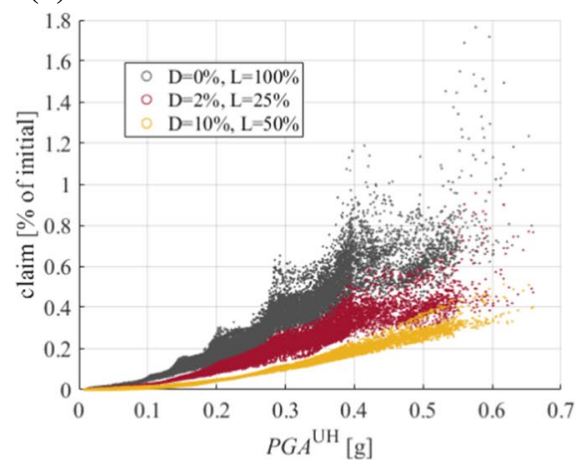

(c)

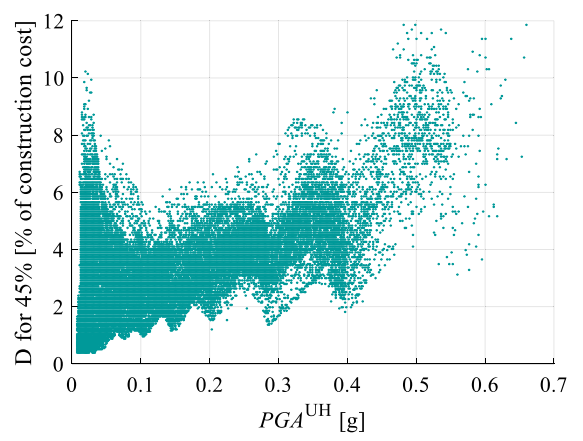

(b)

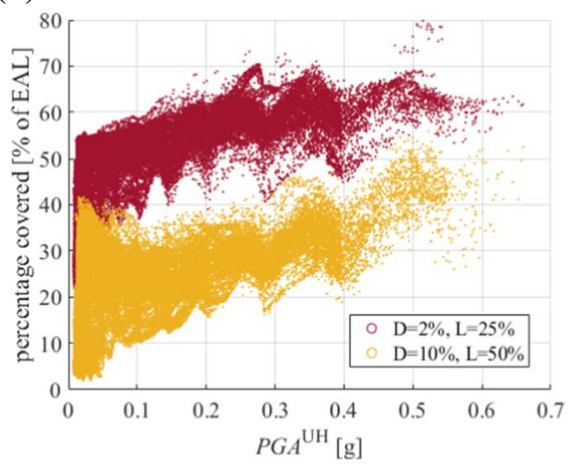

(d)

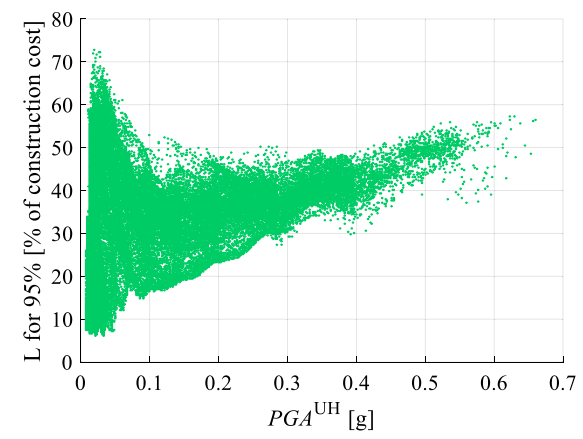

Fig. 11 Results for the structure designed only for gravity loads: a claim and $\mathbf{b}$ percentage of EAL covered, for the different insurance models; points where the c $45 \%$ and $\mathbf{d} 95 \%$ of the EAL are concentrated

The above procedure is repeated considering the structure designed only for gravity loads $\left(\mathrm{PGA}_{\mathrm{d}}=0\right)$. The results are summarized in Fig. 11. As expected, the claim (Fig. 11a) is much higher than for the previous case study, with the maximum value for full insurance equal to $1.76 \%$. When the partial insurance models b $(D=10 \%, L=50 \%)$ and c $(D=2 \%$, $L=25 \%$ ) are implemented, then these percentages are $0.51 \%$ and $0.96 \%$, respectively. The percentage of the EAL covered (Fig. 11b) ranges from 2 to $56 \%$ and 19 to $80 \%$, for models b and c, and is generally higher than $15 \%$ and $40 \%$ in the high seismicity regions. The deductible (Fig. 11c) and limit (Fig. 11d) points vary from 0.4 to $12 \%$ for model b, and 6 to $73 \%$ for model c. The general trend suggests a value of $D$ between 2 and $10 \%$, and a value of $L$ between 20 and $50 \%$.

\section{Sensitivity of the estimates to the uncertainty in the hazard}

As mentioned before, the estimates used in a risk management framework are sensitive to the epistemic uncertainties associated with the hazard input. For example, Fig. 12a and Fig. 12b show the 84th and 50th percentile hazard maps from the current Italian national seismic hazard assessment produced by INGV (Gruppo di Lavoro MPS 2004; Meletti and Montaldo 2007). The uncertainty results from multiple seismic source 
(a)

\begin{tabular}{|c|}
\hline$P G A[\mathrm{~g}]$ \\
$0.04-0.05$ \\
$0.05-0.10$ \\
$0.10-0.15$ \\
$0.15-0.20$ \\
$0.20-0.25$ \\
$0.25-0.30$ \\
$0.30-0.35$ \\
$0.35-0.40$ \\
$0.40-0.49$ \\
\hline
\end{tabular}

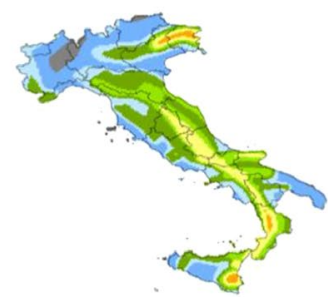

(b)

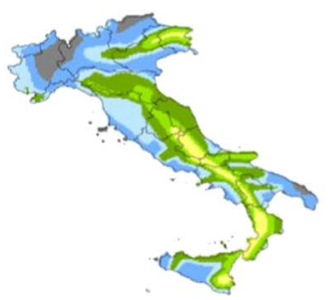

(c)

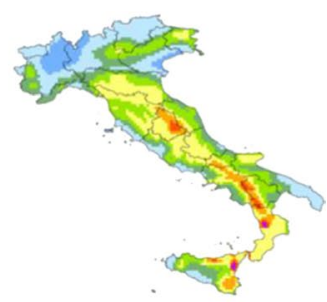

Fig. 12 PGA (site class A) for 475-year return period: a 84th percentile from INGV, b median (50th percentile) from INGV, c median $\left(50^{\text {th }}\right.$ percentile) from ESHM13

zonations and many ground-motion models within the logic tree of the seismic hazard assessment (see, e.g., Douglas et al. 2014 for a discussion of these uncertainties and their sizes in recent seismic hazard assessments). The difference in the PGAs for the 84th and 50th percentiles for a given site ranges between $0.005 \mathrm{~g}$ and $0.063 \mathrm{~g}$, according to Stucchi et al. (2011), who report higher differences when comparing the 84th and 16th percentiles (up to $0.12 \mathrm{~g}$ ).

Differences can be observed between the results from different studies for the same area, too, as it can be inferred by comparing the results of Fig. 12b with those of Fig. 12c, showing the 50th percentile (median) PGAs obtained from the ESHM13. A comparison between the uncertainties for PGAs and response pseudo-spectral accelerations at $1 \mathrm{~s}$ obtained from different hazard studies and for different percentiles can be found in Douglas et al. (2014). The impact of the hazard uncertainty on the safety of the designed structures and the cost implications are investigated in the following sections by considering various case studies.

\subsection{Epistemic uncertainty from different seismic hazard models: case study for Italy}

Four different locations are considered in Italy (Fig. 13a), for which the hazard curves (50th percentiles) in terms of MAF of exceedance of the PGA (Fig. 13b) are obtained from the INGV and ESHM13 projects. The latter gives higher values of PGAs for the 475 -year return period, in the considered areas, as can also be noticed in Fig. 12. That is not the case for the whole range of the PGA levels though, because the slopes of the INGV curves are generally steeper than those from the ESHM13 project and hence the INGV curves often show higher PGAs at higher MAFs.

In the selected locations, the values of the PGAs corresponding to a 475-year return period are found to be $40 \%$ to $95 \%$ higher for the ESHM13 compared to INGV, as shown in Table 2. These differences in the hazard estimates result in different design accelerations for the reference building, which is translated into different construction costs. The structural performance is also changed, and this affects the risk and loss levels from the expected future seismic activity. These are quantified following the procedure outlined in Sect. 2 and the results are reported in Table 2. EAL ${ }^{\mathrm{r}}$ and $E\left[\mathrm{LCC}^{\mathrm{r}}\right]$ refer to the expected value of the annual losses and of the life-cycle cost when only the repair/replacement costs are considered. When the additional losses are also included in the estimates, the notation is changed to $\mathrm{EAL}^{\mathrm{r}, \mathrm{a}}$ and $\mathrm{E}\left[\mathrm{LCC}^{\mathrm{r}, \mathrm{a}}\right]$. It is clarified that class $\mathrm{B}$ is assumed for the soil 
(a)

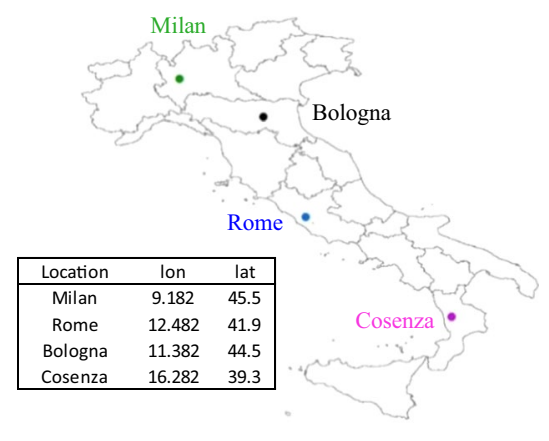

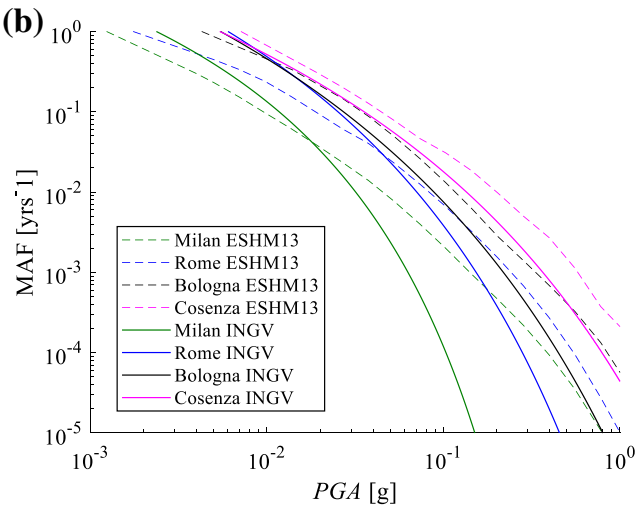

Fig. 13 Case study for Italy: a selected locations, b hazard curves (site class A) of the locations from two projects

Table 2 Comparison of the results for the hazard curves according to the INGV and ESHM13 hazard models

\begin{tabular}{lllllllll}
\hline Location & Project & PGA $^{\mathrm{UH}}[\mathrm{g}]$ & $\mathrm{C}_{0}[€]$ & $\mathrm{EAL}^{\mathrm{r}}[€]$ & $\mathrm{E}\left[\mathrm{LCC}^{\mathrm{r}}\right][€]$ & $\mathrm{EAL}^{\mathrm{r}, \mathrm{a}}[€]$ & $\mathrm{E}[\mathrm{LCC}]^{\mathrm{r}, \mathrm{a}}[€]$ & $\lambda_{C}\left[\mathrm{yrs}^{-1}\right]$ \\
\hline Milan & INGV & 0.05 & 656,323 & 62 & 657,917 & 115 & 659,294 & $8.13 \cdot 10^{-7}$ \\
& ESHM13 & 0.10 & 656,821 & 241 & 663,049 & 821 & 678,091 & $2.61 \cdot 10^{-5}$ \\
& dif. [\%] & 95.1 & 0.1 & 290.7 & 0.8 & 616.0 & 2.9 & 3110.1 \\
Rome & INGV & 0.12 & 658,626 & 438 & 669,956 & 1070 & 686,328 & $1.53 \cdot 10^{-5}$ \\
& ESHM13 & 0.18 & 663,719 & 541 & 677,734 & 1829 & 711,079 & $5.78 \cdot 10^{-5}$ \\
& dif. [\%] & 46.1 & 0.8 & 23.7 & 1.2 & 71.0 & 3.6 & 278.0 \\
Bologna & INGV & 0.17 & 662,937 & 595 & 678,333 & 1722 & 707,538 & $4.13 \cdot 10^{-5}$ \\
& ESHM13 & 0.23 & 669,049 & 887 & 692,010 & 3246 & 753,119 & $1.17 \cdot 10^{-4}$ \\
& dif. [\%] & 39.8 & 0.9 & 49.1 & 2.0 & 88.5 & 6.4 & 182.5 \\
Cosenza & INGV & 0.27 & 672,708 & 977 & 698,016 & 3460 & 762,300 & $1.13 \cdot 10^{-4}$ \\
& ESHM13 & 0.44 & 687,594 & 1379 & 723,292 & 4818 & 812,354 & $1.49 \cdot 10^{-4}$ \\
& dif. [\%] & 60.2 & 2.2 & 41.1 & 3.6 & 39.3 & 6.6 & 31.3 \\
\hline
\end{tabular}

conditions in every location; thus the hazard curves are multiplied by the soil factor 1.2, expressing the ratio between PGAs on site classes B and A in EC8.

First, the initial construction cost is calculated considering as design acceleration, $\mathrm{PGA}_{\mathrm{d}}$, the PGA ${ }^{\mathrm{UH}}$ values with a $10 \%$-in-50-years exceedance probability. Because the initial construction costs are not very sensitive to the design acceleration, the relative differences for the two hazard models are less than $2.2 \%$ for the various sites. It is also important to mention that the variation of the initial cost in the vicinity of $0.1 \mathrm{~g}$ is very low, as discussed in Gkimprixis et al. (2020). This explains why the impact of the considered hazard uncertainty on the construction cost is negligible for Milan (low hazard) and much larger for Cosenza (high hazard).

The MAF of collapse, $\lambda_{C}$, evaluated via Eq. (1), is very sensitive to the hazard model choice, and the variations can be of two orders of magnitude from the estimates obtained considering the hazard from one project rather than the other. These results give a measure of the importance of considering hazard uncertainty in risk assessment. 
The life-cycle cost derives from the sum of the initial costs and the expected future losses evaluated from Eq. (4) for a 50-year time period and a discount rate of $3 \%$ per year. It is noticed that the life-cycle cost is less sensitive to the hazard uncertainty than the risk. This is mainly because the construction cost (which is not very sensitive to the PGA $\mathrm{d}_{\mathrm{d}}$ ) contributes more than the future losses to the E[LCC]. Nevertheless, the relative variation of $\mathrm{E}\left[\mathrm{LCC}^{\mathrm{r}}\right]$ (up to $4 \%$ ) is higher than that of the construction cost. Higher variations in the life-cycle cost are observed if the additional losses are included.

\subsection{Sensitivity analysis for Europe based on a simplified approach}

This section investigates, through a sensitivity study, the effect of the uncertainty in the hazard input on the design and consequently on the risk and loss levels attained for the same reference building considered in the previous sections. To demonstrate the approach, five locations of different seismicity are first studied in detail, and then the procedure is repeated for all locations across Europe.

First, the same locations selected in Sect. 3.2 (Fig. 5) are considered here. A simple approach is followed to investigate the effect of hazard uncertainty, by assuming that the hazard curves of Fig. 5b, considered as the 'reference' ones, underestimate or overestimate the PGA levels by $50 \%$ at all the MAFs of exceedance. This corresponds to a translation of the hazard curves towards the left or the right. It is clarified that the variation in the hazard curves is described by the variations of the PGA for a given MAF, rather than by variations of the MAF for a given PGA, which would not lead to exactly the same results but the overall conclusions would likely be similar.

The varied curves are assumed to describe the actual hazard of the site, which is different than that described by the 'reference' one, and thus will be referred to hereafter as the 'true' curves. Having defined the 'reference' and the 'true' curves, the values of $\lambda_{c}, \mathrm{C}_{0}$, EAL, E[LCC] are calculated for three different cases (based on the consideration of the uncertainty in the design and assessment stages):

- 'Case 1' $(R / T)$ : the building is designed with the 'reference' $(\mathrm{R})$ curve, and the performance is assessed by evaluating the output parameters of interest using the 'true' $(\mathrm{T})$ ones (i.e. varied by $50 \%$, higher or lower than the 'reference' one), which could refer to a case where the building has already been designed for a hazard level, but at the assessment stage the hazard input is updated;

- 'Case 2' (T/T): the 'true' (varied) hazard curves are used both for the design and the assessment of the various output parameters, corresponding to the situation where the true hazard at a site is known at both the stages;

- 'Case 3' $(R / R)$ : the design and assessment of the building are both performed using the 'reference' curve, which corresponds to a situation of reduced knowledge of the true hazard.

Then, sensitivity analyses are performed, by comparing the results obtained from the above three cases to each other. Figure 14 summarizes the various analyses performed, using the results from the above cases. The local sensitivity of the generic parameter $p$ (e.g. initial cost, risk, loss, life-cycle cost) is defined as follows:

$$
\Delta p[\%]=\left(p_{B}-p_{A}\right) \cdot 100 / p_{A}
$$



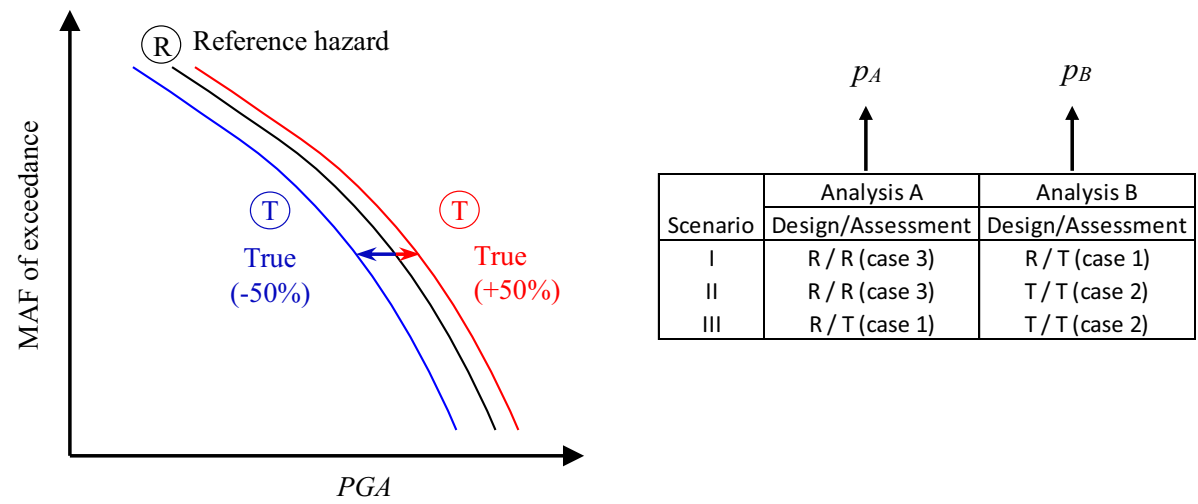

Fig. 14 Summary of the scenarios considered within the sensitivity analyses $(R=$ Reference, $T=$ True)

where $p_{A}$ denotes the value of the parameters obtained from analysis A (for either 'Case 3 ' or 'Case 1'), and $p_{B}$ denotes the value of the parameters obtained from analysis 2 (for either 'Case 1' or 'Case 2'), as defined in Fig. 14. The values of $\Delta p$ provide information on the sensitivity of costs, losses, and safety to the hazard, for different sites, thus allowing quantification of the importance of a more accurate hazard assessment.

\subsubsection{Scenario I: 'Case 3' versus 'Case 1'}

In the first scenario, a comparison is made between the results obtained from 'Case 3' versus those obtained from 'Case 1'. Figure 15 shows the results obtained based on Eq. (8), for the five considered locations. The red and blue points refer to the cases of respectively higher and lower 'true' hazards compared to the 'reference' one (i.e. hazard underestimated and overestimated by the 'reference' curve, respectively). Given that the design in both cases is performed with the 'reference' hazard curve, the initial construction costs are the same. The rest of the output parameters are all increased or decreased when the 'true' curve is higher or lower, respectively, than the 'reference' one. It is interesting to observe that the estimated values are not symmetrical around zero, although the design is the same and the hazard is increased and decreased by the same percentage. This is attributed to the fact that the fragility and vulnerability functions are not constant, but change with the IM level, resulting in higher sensitivity when the hazard is increased rather than decreased.

It can also be observed that the parameter that is most sensitive to the hazard uncertainty is the risk (differences of up to $200 \%$ ). Of course, it is important to have in mind that
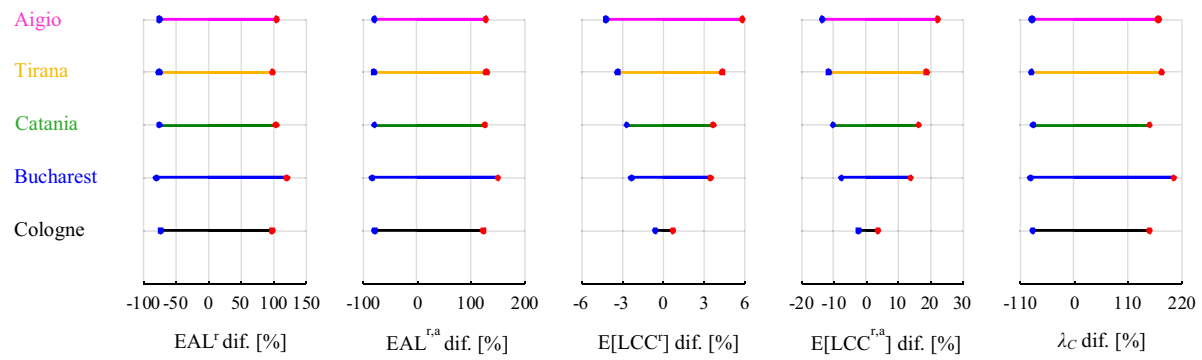

Fig. 15 Variation of the studied parameters for Scenario I 
the risk is very small in absolute terms. The EALs are also very sensitive to the hazard (differences of up to $150 \%$ ), though the actual numbers are quite small compared to the initial cost. The variation of the E[LCC] is lower, given that it is affected mainly by the change in the initial cost, which is zero in this scenario. It is interesting that the seismic hazard of the site does not play an important role in the sensitivity of the considered parameters, with the exception of the E[LCC].

This type of investigation can be used, for example, to incorporate uncertainties to the insurance model suggested above. For example, the minimum premium (equal to the EAL ${ }^{r}$ in the case of full insurance) for Aigio should be increased by a percentage higher than the assumed hazard uncertainty, i.e. by $75 \%$ and $105 \%$ when the hazard is decreased or increased, respectively, by $50 \%$.

\subsubsection{Scenario II: 'Case 3' versus 'Case 2'}

A second sensitivity analysis is performed, where a comparison is carried out between the results for 'Case 3' and 'Case 2'. The sensitivities of all the parameters in the assessed locations are calculated according to Eq. (8), and the results are presented in Fig. 16. This investigation highlights the effects of updating the design, previously done with the 'reference' hazard, based on the 'true' hazard. In contrast to the previous scenario, now the construction cost is changed to meet the true hazard needs. Because of the updated design, the variation of the rest of the parameters is reduced, in comparison with the previous scenario. Also, the variation of the parameters is more dependent on the seismic hazard of the location in contrast to the previous scenario.

\subsubsection{Scenario III: 'Case 1'versus 'Case 2'}

A final sensitivity analysis is performed by comparing the results obtained from 'Case 1 ' versus those obtained from 'Case 2'. The results of this sensitivity analysis for the five locations are presented in Fig. 17. As expected, if the design is carried out assuming a 'true' hazard that is higher than the 'reference' (red points), then the initial construction cost increases, but on the other hand there is a reduction of the risk and losses. The opposite applies in the case of a 'true' hazard that is lower than the 'reference' one (blue points). The life-cycle cost variations are influenced by changes in both the initial cost and the future losses, and thus they do not follow a constant trend. It can also be observed that the parameter that is most sensitive to the hazard uncertainty is
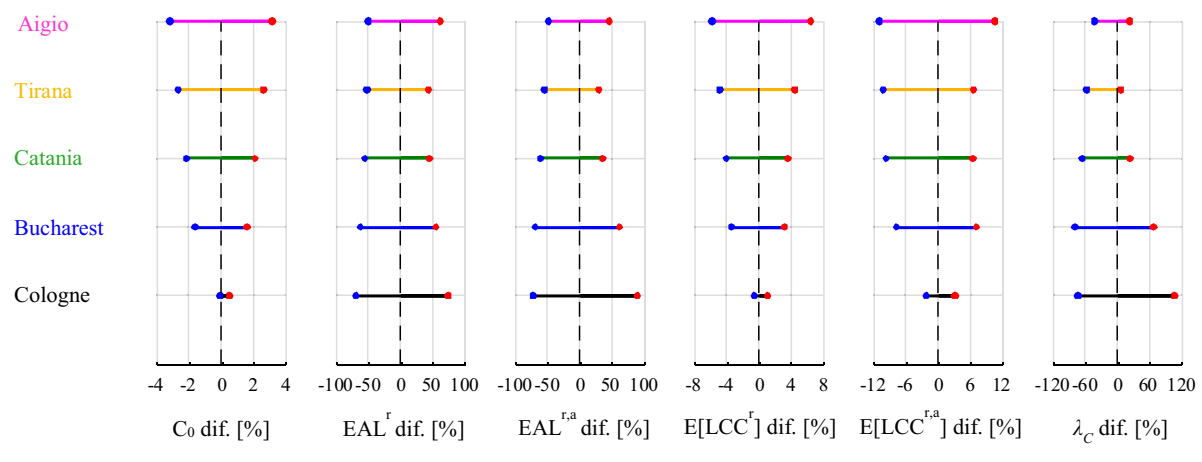

Fig. 16 Variation of the studied parameters for Scenario II 


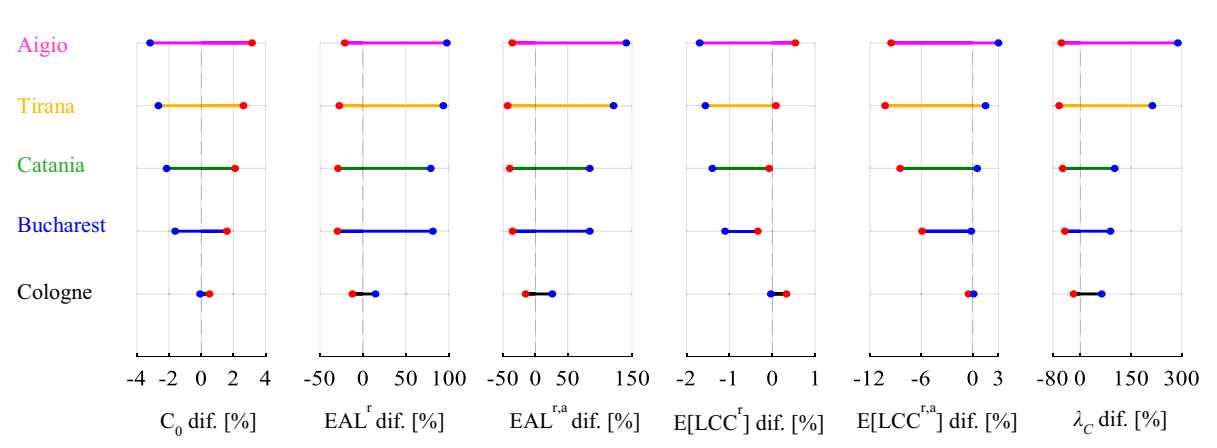

Fig. 17 Variation of the studied parameters for Scenario III

the risk. Of course, it is important to have in mind that the risk values are very small numbers. In Aigio, for example, if the 'true' hazard is lower than the 'reference' one used for the design, the risk is $2.58 \cdot 10^{-5}$. This is significantly lower than the risk corresponding to the design performed using the 'true' hazard curve, which is $1.00 \cdot 10^{-4}$ (i.e. $289 \%$ higher). For the rest of the parameters, it is clear that the differences are in general greater in higher hazard areas than in lower hazard areas (e.g. Cologne). This suggests that $\pm 50 \%$ differences in hazard are relatively unimportant in low hazard areas and hence there is less need to refine hazard assessments there. It should be noted, however, that only a single building type and geometry is considered here and hence more analyses are required before drawing wider conclusions.

The EALs are very sensitive to the hazard, with a maximum difference of $-30 \%$ and $98 \%$ in the case of underestimation and overestimation of the hazard, respectively. On the other hand, the sensitivity of the initial cost is lower than $4 \%$, given that the initial cost does not present a significant variation for the different design levels (see Fig. 18a). Although the EALs are significantly affected by the hazard variations, the actual numbers are quite small compared to the initial cost. Thus, the E[LCC] exhibits a reduced sensitivity, being affected mainly by the change of the initial cost.

The graph for the initial cost is almost symmetrical, meaning that under- and overestimating the hazard has roughly the same effect in absolute terms. That is not the case for the other studied parameters. For example, the impact of overestimating the hazard ('true' hazard curve 50\% smaller than the 'reference' one) on the EAL is higher than when the hazard is underestimated.

To better understand these trends, the location of Catania is selected for further investigation. Figure $18 \mathrm{a}$ shows the relation between the initial cost $\mathrm{C}_{0}$ (normalized to the one for $\mathrm{PGA}_{\mathrm{d}}=0$, i.e. 655,840€) and the design acceleration. This relationship is almost linear for $\mathrm{PGA}_{\mathrm{d}}$ values higher than $0.1 \mathrm{~g}$. This is why the $50 \%$ increased or decreased hazard results in roughly $2 \%$ change of $\mathrm{C}_{0}$ in both cases. Figure $18 \mathrm{~b}$ shows the results in terms of EAL, normalized to those corresponding to $\mathrm{PGA}_{\mathrm{d}}=0$ for each case (i.e., $729 €, 2,357 €$, and 4,362€ for $-50 \%$, 'reference', and $+50 \%$, respectively). For reference, a black curve is also plotted which corresponds to considering the 'reference' hazard curve both for design and assessment ('Case 3' above). The EALs are also evaluated again considering the 'reference' hazard curve only for design while the assessment is done with the curve increased by $50 \%$ (red line) or decreased by $50 \%$ (blue line). Similarly, the colour of the dots shows which hazard curve was used for the design. 
(a)

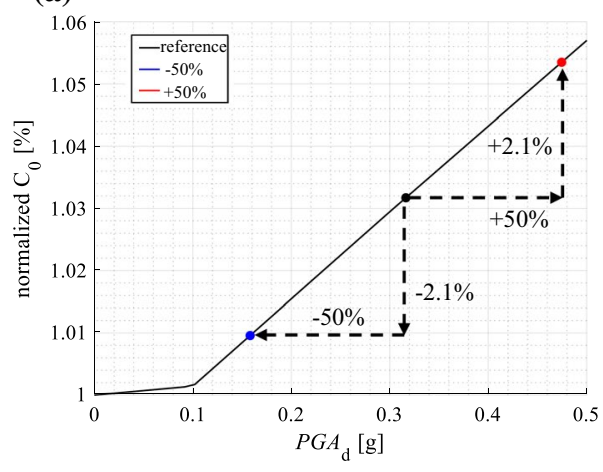

(b)

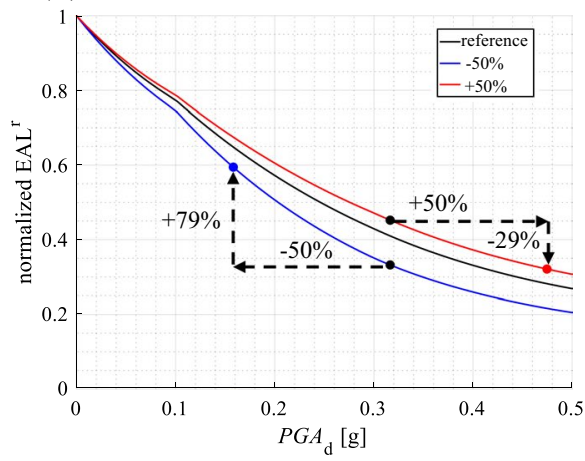

Fig. 18 Impact of the difference between design and actual hazard on $\mathbf{a} \mathrm{C}_{0}$ and $\mathbf{b} \mathrm{EAL}$
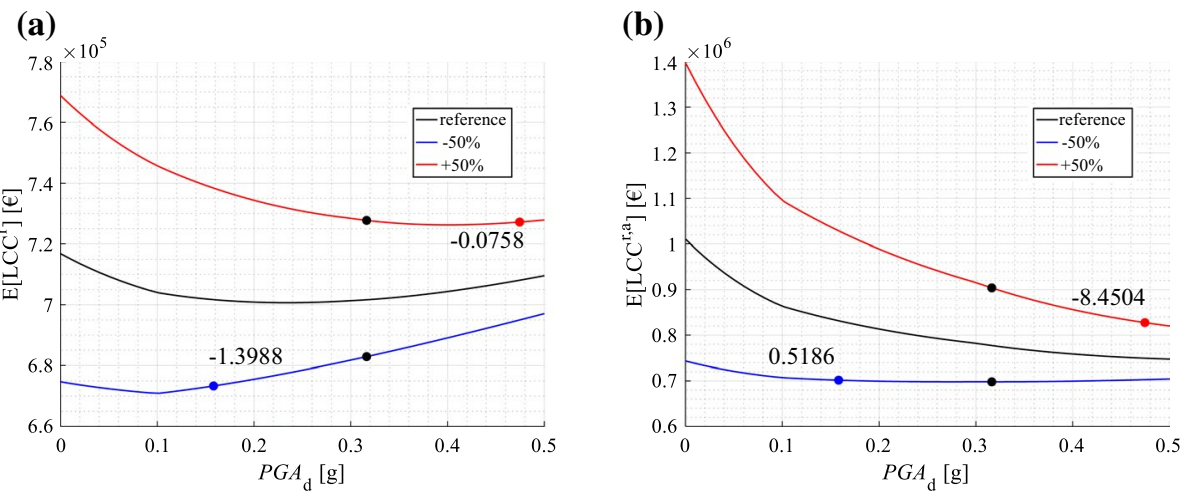

Fig. 19 Impact of the difference between design and actual hazard curve on $E\left[L^{2} C^{\mathrm{r}, a}\right]$ considering: a only the repair costs, and $\mathbf{b}$ the repair costs and additional losses

The same sensitivity study is performed for the E[LCC] and the results are presented in Fig. 19a, b, with the additional losses disregarded or considered along with the repair/ replacement cost, respectively. In this case, the hazard uncertainty does not affect the lifecycle costs in a consistent direction, as mentioned before. This is attributed to the fact that the relation of LCC with the $\mathrm{PGA}_{\mathrm{d}}$ is not monotonic, given that the initial cost and the future losses are affected in opposite ways by a change in the $\mathrm{PGA}_{\mathrm{d}}$.

\subsubsection{Investigation across Europe}

In this section, the effect of the hazard uncertainty on the cost and performance of the structure is investigated for all locations across Europe. As explained in Sect. 3.2, first, the PGA values that correspond to various exceedance probabilities for the different locations are obtained from the ESHM13 project and the second-order polynomial function in log-space (Vamvatsikos 2013) is used to extrapolate the hazard data to a wider range of PGA, if required. As the seismic designs were undertaken using the EC8 spectrum for site class B, the PGAs for site class A from the ESHM13 are multiplied by the soil factor 1.2, 
expressing the ratio between PGAs on site classes B and A in EC8, to construct the 'reference' hazard curves. These PGAs are further increased or decreased by $50 \%$ to perform the sensitivity analyses. In order to avoid biasing the conclusions by extrapolating the vulnerability curves to very high values of PGA (e.g. $0.60 \mathrm{~g}$ would become $0.90 \mathrm{~g}$ for a $50 \%$ increased hazard) the results presented here refer to PGAs up to $0.5 \mathrm{~g}$.

The first column of Fig. 20 presents the values of $\mathrm{C}_{0}$ (normalized to the value for $\mathrm{PGA}_{\mathrm{d}}=0$, i.e. 655,840€), EAL, E[LCC] (both normalized to the $\mathrm{C}_{0}$ value of each location) and $\lambda_{c}$, for all the considered locations across Europe. The parameters are evaluated for 'Case 3' (defined above), and the resulting values are summarized in the first column of Fig. 20 versus the value of the 475 -year-return-period $\mathrm{PGA}^{\mathrm{UH}}$. Each point refers to a given location across Europe, for example the figure for the EAL ${ }^{\mathrm{r}}$ summarizes Figs. 7a and 6 (see explanation in Fig. 8). Similarly, the remaining graphs of the column summarize the values of the parameters for all locations across Europe. These results have already been discussed (and presented as maps) in Gkimprixis et al. (2020), but are summarized here to help with the interpretation of the sensitivity analyses.

The variations in $\mathrm{C}_{0}$, EAL, E[LCC] and $\lambda_{c}$ for all the considered locations across Europe are then calculated based on Eq. (8). In particular, in the second column of Fig. 20, the sensitivity of the parameters is evaluated for 'Case 3' and 'Case 1' and in the third column by comparing 'Case 3' and 'Case 2'. The resulting variations show how much the values of the first column will be affected, considering the hazard uncertainty described by Scenarios I and II.

The trends are similar in both scenarios, for all the considered parameters, in the sense that the results of both cases present the same trend (increased or decreased) as the hazard variation. Overall, it can be observed that overestimating hazard ('true' lower than 'reference', i.e. blue points) introduces lower levels of uncertainty in the estimates, when compared to the case of underestimation of hazard. The most sensitive parameters are the EAL and the risk, mainly in low seismicity regions and for the case of underestimating hazard (red points). In the second scenario the levels of uncertainty in the high seismicity regions are smaller and close to level of the hazard uncertainty. The variation of $\mathrm{E}[\mathrm{LCC}]$ is mainly affected by the variation in $\mathrm{C}_{0}$, and are both lower than the hazard uncertainty.

For the second scenario (third column of Fig. 20) and for PGA ${ }^{\mathrm{UH}}$ values higher than $0.1 \mathrm{~g}$, the variations of $\mathrm{C}_{0}$ due to increased or decreased hazards are almost symmetrical. This is a consequence of the relation between $\mathrm{C}_{0}$ and the design acceleration, which is almost linear for $\mathrm{PGA}^{\mathrm{UH}}$ values higher than $0.1 \mathrm{~g}$ (see plot for $\mathrm{C}_{0}$ in first column of Fig. 20). In the vicinity of $0.1 \mathrm{~g}$ the change in $\mathrm{C}_{0}$ when the hazard is reduced by $50 \%$ is smaller than when the hazard is increased (see also Fig. 18a). This is attributed to the minimum requirements of the design code and the fact that for low levels of $\mathrm{PGA}_{d}$ the design is mainly influenced by the gravity loads. This leads to an overdesign in the case of $\mathrm{PGA}_{\mathrm{d}}=0$, influencing the slopes of the $\mathrm{C}_{0}$ and EAL curves (Fig. 19a, b).

As previously discussed, the EAL ${ }^{r}$ variation graphs can be used to account for the effects of hazard uncertainty on insurance premiums. If the 'true' hazard is different to the 'reference', then the premiums obtained from 'Case 3' (Fig. 7a or the equivalent graph of EAL $^{r}$ in the first column of Fig. 20) should be modified by the percentages reported in the second and the third column, if the design is performed with the 'reference' or the updated/ 'true' hazard model, respectively. It is worth noting that in many cases the level of uncertainty introduced in the insurance model is more than twice that of the hazard uncertainty (assumed 50\%) for Scenario I, which is reduced to roughly equal the hazard uncertainty when the design is updated to match the 'true' hazard (Scenario II). 


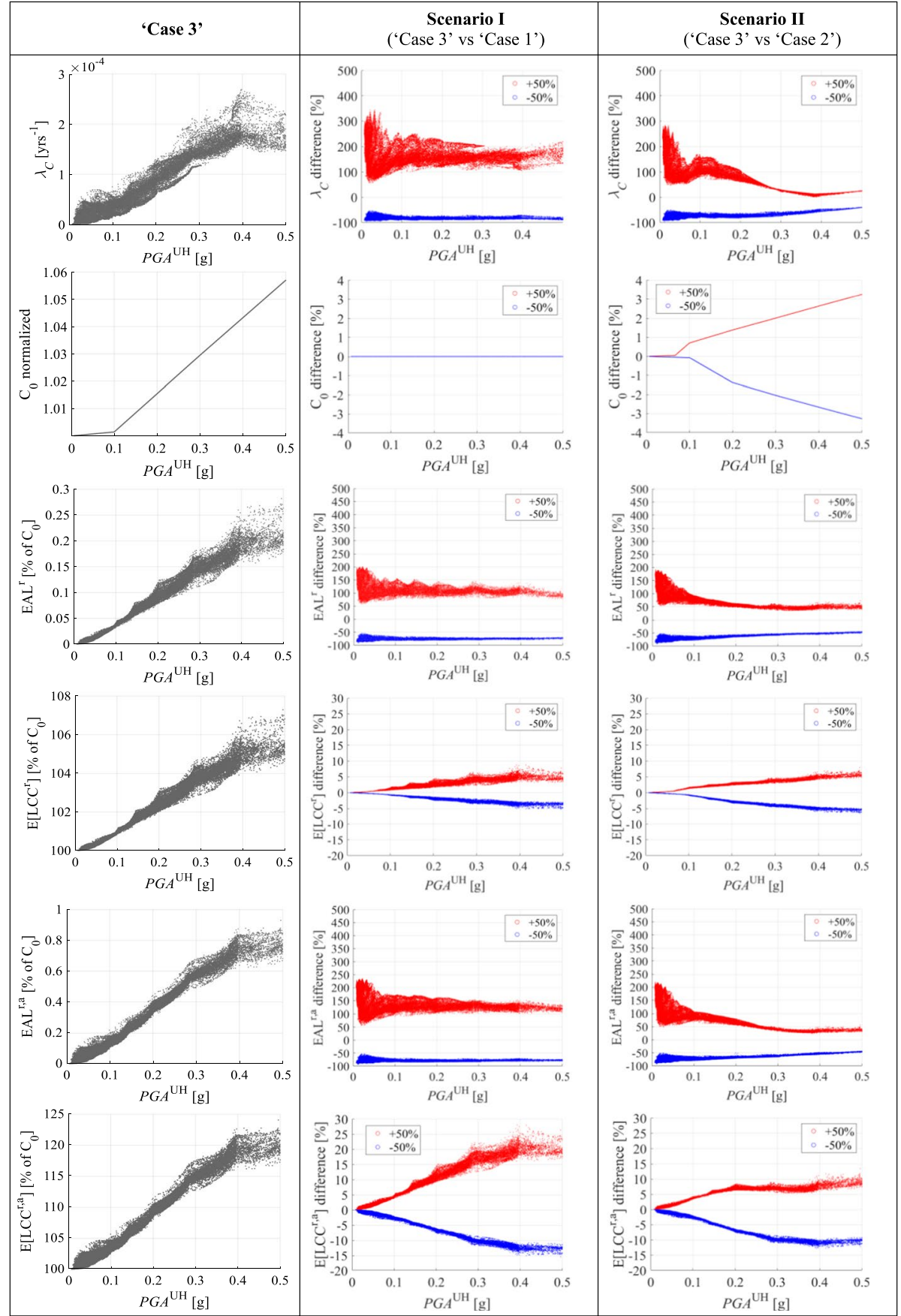

Fig. 20 Investigation across Europe: parameters obtained from the analysis for 'Case 3' (left) and their variation based on the analyses associated with Scenario I (middle) and with Scenario II (right) 


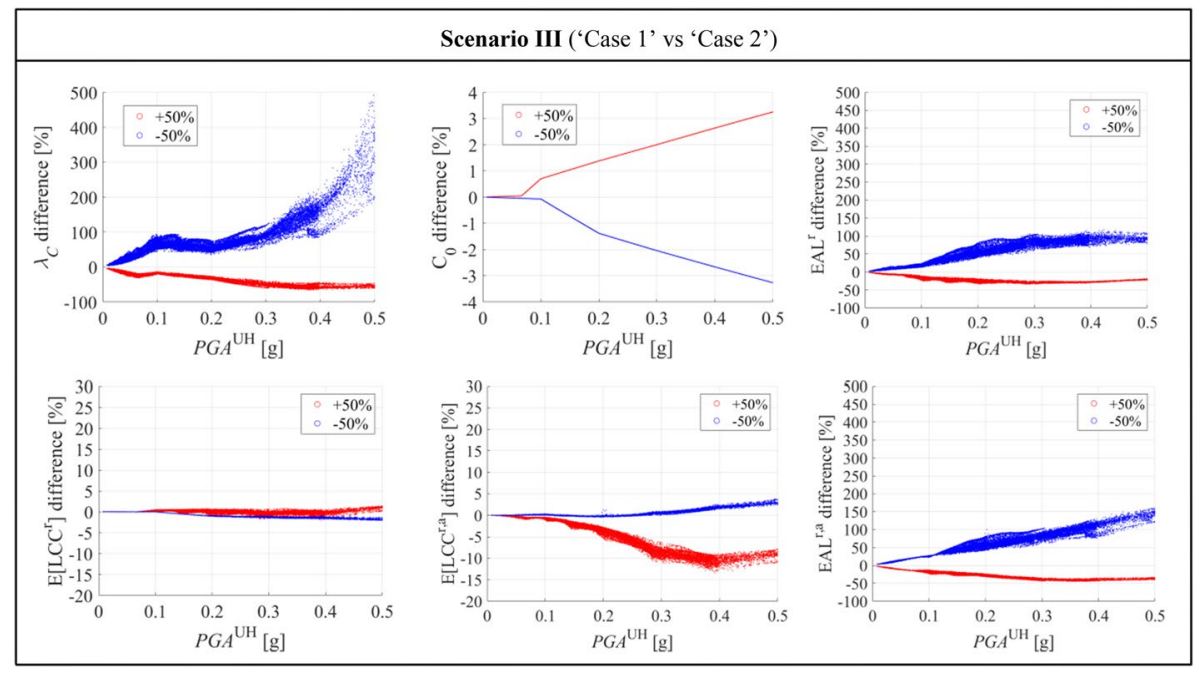

Fig. 21 Results for the studied parameters across Europe based on the analyses associated with Scenario III

The variations in $\mathrm{C}_{0}$, EAL, E[LCC] and $\lambda_{c}$ for all the considered locations across Europe are also calculated for Scenario III, using Eq. (8), and the results are summarized in Fig. 21. It is noted that, in contrast to the two previous scenarios, there is no connection of these results to the first column of Fig. 20 (i.e. with 'Case 3'), since the variations refer to the difference in the estimates resulting from 'Case 1' versus 'Case 2'.

Overall, it can be observed that the effects of the hazard variations change significantly from location to location. For example, the changes in the observed parameters are negligible for low hazard sites with $\mathrm{PGA}^{\mathrm{UH}}$ less than $0.1 \mathrm{~g}$. It should be clarified that this observation is based on analyses for a single example of a code-compliant structure and may not hold for other types of structure or infrastructure. The parameter that is most sensitive to the hazard uncertainty is the risk, for the case of overestimating the hazard. It is observed that, in high seismicity regions, overestimating the actual hazard of the site can lead to underestimation of the risk by up to 500\%. Significant also are the variations of the EAL, which as discussed above for the case of Catania, increase monotonically with $\mathrm{PGA}^{\mathrm{UH}}$, while the E[LCC] does not exhibit a clear trend in its variation.

As previously commented, the results can provide useful information for the insurance sector. For example, the results for the EAL ${ }^{\mathrm{r}}$ (presented in Fig. 20 and in Fig. 21) can be interpreted as the sensitivity of the minimum premium (no profit) in the extreme case of a full insurance contract (no deductible or limit point). Similarly, the sensitivity of the premium in the case of partial insurance can be determined. As an example, the analyses for the three defined scenarios are repeated for the insurance model of Fig. 2a $(D=10 \%$ and $L=50 \%$ ), which significantly changes the insurance premiums, as seen in Fig. 9a.

The results for Scenarios I and II are presented in Fig. 22a, b, respectively. It is very interesting to observe that the effect of the hazard uncertainty on the partial insurance premiums is increased, compared to the case of full insurance investigated above. This effect is larger in areas of low to moderate seismicity (e.g. with a PGA ${ }^{\mathrm{UH}}$ lower than $0.3 \mathrm{~g}$ ) for Scenarios I and II and a 'true' hazard curve 50\% higher than the 'reference' one. It is recalled though that the obtained EALs are quite low in low seismicity regions (see Fig. 9a). For 


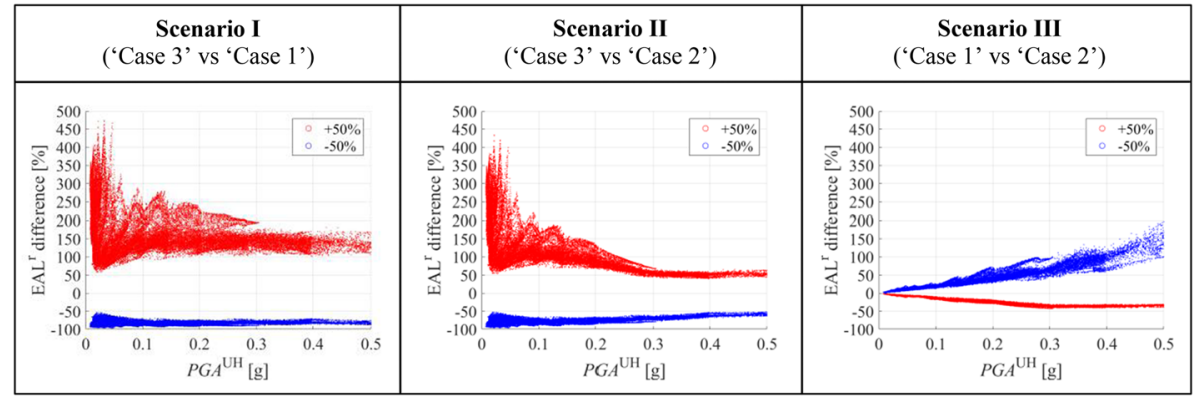

Fig. 22 Comparison of the $\mathrm{EAL}^{\mathrm{r}}$ covered by partial insurance $(D=10 \%$ and $L=50 \%)$ across Europe, obtained from the sensitivity analyses associated with Scenarios I, II and III

Scenario III on the other hand, similar results to the case of full insurance in Fig. 21 are observed in Fig. 22 (observe EAL ${ }^{r}$ results of the two figures), with some increased impacts in high seismicity regions and for the case of a 'true' hazard curve 50\% lower than the 'reference' one.

Overall, from these results it is concluded that the necessary precision in the definition of the hazard curve depends on the parameter of interest. In other words, the need to invest in the accuracy of the hazard model depends on the stakeholder. For example, a study on the risk sensitivity can be of interest when updating design guidelines and defining the design seismic input and the target reliability levels to be achieved. On the other hand, the information on the sensitivity of the EALs would be more useful for insurance companies that cover losses from future earthquakes, since the uncertainties can seriously affect the insurance premiums.

\section{Conclusions}

The first part of this article investigates the management of the expected losses due to damage in structures by future seismic events, through the mechanism of transfer of the financial risk via earthquake insurance. Analyses are carried out considering a case-study building (four-storey, three-bay reinforced-concrete frame building) designed following seismic codes, and various assumptions for the insurance model are examined. Based on the obtained results, the following conclusions can be drawn:

- For the prototype building designed with seismic provisions, the amount that should be charged by insurance companies to cover their expenses (no profit) associated with the case of full insurance (all the expenses for repairing the damage are covered by insurance) is found to vary between 0.15 and $0.35 \%$ (of the construction cost), in high seismicity regions. This amount substantially increases (values between 0.3 and $1.8 \%$ for high seismicity regions) if the prototype building is designed with no seismic design provisions. Of course, these values should be increased for the company to make a profit.

- The expected annual losses are dominated by more frequent events that cause minor damage to the structure. This means that deductibles higher than $10 \%$ result in low 
insurance rates but at the same time the homeowner has to deal with most of the repair costs.

- Sensitivity analyses suggest using low deductible points (between 2 and 5\%) together with limit points between 25 and $50 \%$ to obtain a roughly equal share of the losses between the insurer and owner.

The second part of the article investigates the effects of the epistemic uncertainties inherent in the hazard input definition. First, a comparison between two studies for Italy shows that:

- Significant variations in the hazard are noticeable amongst seismic hazard studies for the same location;

- Significant variation of the hazard is noticed even within the same study (e.g. if we compare the median with other percentiles) due to epistemic uncertainty in the seismic hazard inputs (e.g. zonation, maximum magnitudes and ground-motion models).

Then, the effect of the differences between two hazard models for Italy on the seismic design of structures and consequently on the construction cost, the life-cycle cost and the risk estimates are investigated. To expand the investigation to the whole of Europe, a simplifying approach to model hazard uncertainty is introduced, and various sensitivity analyses are made. The general conclusions are:

- The necessary precision in the definition of the hazard input depends on the parameter of interest, and consequently, the need of investing in the accuracy of the hazard model depends on the stakeholder;

- The initial construction cost presents small variations and consequently the life-cycle cost also does not vary significantly;

- The parameters exhibiting the most significant variations from site to site are the annual collapse risk and the expected annual losses;

- The sensitivity of the insurance premium to the hazard uncertainty depends on the defined deductible and limit points.

More specifically, three scenarios are investigated, and the most important findings are summarized in the following:

- Scenario I: A first analysis is performed in which the design and the assessment are both performed with a 'reference' hazard curve. Then, a different hazard curve, which represents the 'true' hazard by varying the 'reference' one, is defined. The uncertainty introduced in the most sensitive parameters (i.e. the risk and the losses) is higher than that of the hazard;

- Scenario II: The design is changed to meet the 'true' hazard. The change of the design means that the initial construction cost is affected. However, this update reduces the effect of the hazard uncertainty on the parameters (compared to the previous scenario), especially in high seismicity areas; and

- Scenario III: The building has been designed with the 'reference' hazard and assessed with the 'true', in comparison with performing both the design and the assessment with the 'true' hazard. The effects of the hazard variations are negligible for low hazard sites. For high seismicity regions and for overestimating the hazard, the levels of uncertainty 
introduced to the loss and the risk estimates are moderately higher than the assumed hazard uncertainty.

It is highlighted that the investigations refer to a single case-study structure, assumed to be built in all locations across Europe using the same materials and construction costs and hence the conclusions may not hold for other types of structures or other elements at risk.

Acknowledgements The authors would like to thank the two anonymous reviewers for their comments on an earlier version of this article. The work was undertaken during the Ph.D. studies of the first author, funded by the University of Strathclyde through an "Engineering The Future" studentship, for which we are grateful. Finally, we thank the two examiners of the thesis (Dr Flavia De Luca and Prof. Edoardo Patelli) for their comments on this work.

Author contributions All authors contributed to the study conception and methodology. Data collection, formal analyses and investigations were performed by AG. The first draft of the manuscript was written by AG and all authors commented on previous versions of the manuscript. All authors read and approved the final manuscript.

\section{Declarations}

Conflicts of interest The authors have no conflicts of interest to declare that are relevant to the content of this article.

Open Access This article is licensed under a Creative Commons Attribution 4.0 International License, which permits use, sharing, adaptation, distribution and reproduction in any medium or format, as long as you give appropriate credit to the original author(s) and the source, provide a link to the Creative Commons licence, and indicate if changes were made. The images or other third party material in this article are included in the article's Creative Commons licence, unless indicated otherwise in a credit line to the material. If material is not included in the article's Creative Commons licence and your intended use is not permitted by statutory regulation or exceeds the permitted use, you will need to obtain permission directly from the copyright holder. To view a copy of this licence, visit http://creativecommons.org/licenses/by/4.0/.

\section{References}

Belvaux M, Douglas J, Ulrich T (2014) Comparisons between SHARE and current national seismic hazard maps for France. In: Seismic Hazard Harmonization in Europe (SHARE): DGEB-workshop

Bommer J, Spence R, Erdik M, Tabuchi S, Aydinoglu N, Booth E, Del Re D, Peterken O (2002) Development of an earthquake loss model for Turkish catastrophe insurance. J Seismolog 6:431-446

Bradley BA (2009) Seismic hazard epistemic uncertainty in the San Francisco bay area and its role in performance-based assessment. Earthq Spectra 25(4):733-753

CEN (2004a) EN 1992-1-1:2004 Eurocode 2: design of concrete structures-Part 1-1: general rules and rules for buildings. European Committee for Standardization, Brussels

CEN (2004b) EN 1998-1:2004 Eurocode 8: design of structures for earthquake resistance-Part 1: general rules, seismic actions and rules for buildings. European Committee for Standardization, Brussels

Cosenza E, Del Vecchio C, Di Ludovico M, Dolce M, Moroni C, Prota A, Renzi E (2018) The Italian guidelines for seismic risk classification of constructions: technical principles and validation. Bull Earthq Eng 16:5905-5935. https://doi.org/10.1007/s10518-018-0431-8

Crowley H, Silva V, Bal IE, Pinho R (2012) Calibration of seismic design codes using loss estimation. In: Proceedings of 15th world conference on earthquake engineering, Lisbon, Portugal.

Douglas J, Ulrich T, Bertil D, Rey J (2014) Comparison of the ranges of uncertainty captured in different seismic-hazard studies. Seismol Res Lett 85(5):977-985. https://doi.org/10.1785/0220140084

Giardini D et al. (2013) Seismic Hazard Harmonization in Europe (SHARE): Online Data Resource. https:// doi.org/10.12686/SED-00000001-SHARE

Gkimprixis A, Tubaldi E, Douglas J (2020) Evaluating alternative approaches for the seismic design of structures. Bull Earthq Eng 18:4331-4361. https://doi.org/10.1007/s10518-020-00858-4 
Goda K, Wenzel F, Daniell J (2014) Insurance and reinsurance models for earthquake. In: M. Beer, E. Patelli, I.A. Kougioumtzoglou, S.K. Au (Eds.), Encyclopedia of earthquake engineering, Springer, Berlin. https://doi.org/10.1007/978-3-642-36197-5_261-1

Grünthal G, Bosse C, Stromeyer D (2014) Building-code related seismic hazard snalyses of Germany and their Relation to SHARE. In: Seismic Hazard Harmonization in Europe (SHARE): DGEB-workshop (Vol. 27)

Grünthal G, Stromeyer D, Bosse C, Cotton F, Bindi D (2018) The probabilistic seismic hazard assessment of Germany-version 2016, considering the range of epistemic uncertainties and aleatory variability. Bull Earthq Eng 16:4339-4395

Gruppo di Lavoro MPS (2004) Redazione della mappa di pericolosità sismica prevista dall'Ordinanza PCM del 20 marzo 2003 n. 3274, All. 1. Rapporto conclusivo per il Dipartimento della Protezione Civile, aprile 2004, Istituto Nazionale di Geofisica e Vulcanologia (INGV), Milano-Roma, Italy, available at http://zonesismiche.mi.ingv.it/

Kappos AJ, Dimitrakopoulos EG (2008) Feasibility of pre-earthquake strengthening of buildings based on cost-benefit and life-cycle cost analysis, with the aid of fragility curves. Nat Hazards 45(1):33-54

Kennedy RP (2011) Performance-goal based (risk informed) approach for establishing the SSE site specific response spectrum for future nuclear power plants. Nucl Eng Des 241:648-656

Kunreuther H (1993) Earthquake insurance as a hazard reduction strategy: The case of the homeowner. In 1993 National Earthquake Conference "Earthquake Hazard Reduction in the Central and Eastern United States: A Time for Examination and Action”, Central United States Earthquake Consortium (CUSEC)

Lagaros ND (2007) Life-cycle cost analysis of design practices for RC framed structures. Bull Earthq Eng 5(3):425-442

Maccaferri S, Cariboni F, Campolongo F (2011) Natural Catastrophes: risk relevance and insurance coverage in the EU. European Commission, Joint Research Centre

Martin Ch, Combes P, Secanell R, Lignon G, Fioravanti A, Carbon D, Monge O, Grellet B, Révision du zonage sismique de la France, étude probabiliste. Ministère de 1“Aménagement du Territoire et de I"Environnement. Rapport GEOTER GTR/MATE/0701-150, 2002, in French

Meletti C, Montaldo V (2007) Stime di pericolosità sismica per diverse probabilità di superamento in 50 anni: valori di ag. Progetto DPC-INGV S1, Deliverable D2, http://esse1.mi.ingv.it/d2.html

Michel GW (2014) Decision making under uncertainty: insuring and reinsuring earthquake risk. In: Earthquake hazard, risk and disasters. Academic Press, pp. 543-568. https://doi.org/10.1016/B978-0-12394848-9.00021-3

Motamed H, Calderon A, Silva V, Costa C (2019) Development of a probabilistic earthquake loss model for Iran. Bull Earthq Eng 17:1795-1823

Olshansky RB (2005) Making a difference: Stories of successful seismic safety advocates. Earthq Spectra 21(2):441-464. https://doi.org/10.1193/1.1902953

Ordaz M, Salgado-Gálvez MA, Pérez-Rocha LE, Cardona OD, Mena-Hernández U (2017) Optimum earthquake design coefficients based on probabilistic seismic hazard analyses: theory and applications. Earthq Spectra 33(4):1455-1474. https://doi.org/10.1193/110116eqs189m

Padgett JE, Dennemann K, Ghosh J (2010) Risk-based seismic life-cycle cost-benefit (LCC-B) analysis for bridge retrofit assessment. Struct Saf 32(3):165-173

Pakdel-Lahiji N, Hochrainer-Stigler S, Ghafory-Ashtiany M, Sadeghi M (2015) Consequences of financial vulnerability and insurance loading for the affordability of earthquake insurance systems: evidence from Iran. The Geneva Papers 40:295-315. https://doi.org/10.1057/gpp.2014.35

Palm R (1995) Earthquake insurance: a longitudinal study of California homeowners. Westview Press, Boulder

Pavel F, Vacareanu R, Douglas J, Radulian M, Cioflan C, Barbat A (2016) An updated probabilistic seismic hazard assessment for Romania and comparison with the approach and outcomes of the SHARE project. Pure Appl Geophys 173:1881-1905. https://doi.org/10.1007/s00024-015-1223-6

Ramirez CM, Liel AB, Mitrani-Reiser J, Haselton CB, Spear AD, Steiner J, Deierlein GG, Miranda E (2012) Expected earthquake damage and repair costs in reinforced concrete frame buildings. Earthquake Eng Struct Dynam 41(11):1455-1475

Shinozuka M, Feng Q, Lee J, Naganuma T (2000) Statistical analysis of fragility curves. J Eng Mech 126:1224-1231

Spence R (2007) Saving lives in earthquakes: successes and failures in seismic protection since 1960. Bull Earthq Eng 5:139-251. https://doi.org/10.1007/s10518-006-9028-8

Stucchi M, Meletti C, Montaldo V, Crowley H, Calvi GM, Boschi E (2011) Seismic Hazard Assessment (2003-2009) for the Italian Building Code. Bull Seismol Soc Am 101(4):1885-1911. https://doi.org/ $10.1785 / 0120100130$ 
Vamvatsikos D (2013) Derivation of new SAC/FEMA performance evaluation solutions with second-order hazard approximation. Earthquake Eng Struct Dynam 42(8):1171-1188

Vamvatsikos D, Cornell CA (2002) Incremental dynamic analysis. Earthquake Eng Struct Dynam 31(3):491-514

Wen YK, Kang YJ (2001) Minimum building life-cycle cost design criteria. II: Applications. J Struct Eng 127(3):338-346

Woessner J, Danciu L, Giardini D, Crowley H, Cotton F, Grunthal G, Valensise G, Arvidsson R, Basili R, Demircioglu MB, Hiemer S, Meletti C, Musson RW, Rovida AN, Sesetyan K, Stucchi M, The SHARE Consortium (2015) The 2013 European Seismic Hazard Model: Key components and results. Bull Earthq Eng 13(12):3553-3596. https://doi.org/10.1007/s10518-015-9795-1

Yoshikawa H, Goda K (2014) Financial seismic risk analysis of building portfolios. Nat Hazard Rev 15(2):112-120

Yucemen MS (2013) Probabilistic assessment of earthquake insurance rates for buildings. In: Handbook of seismic risk analysis and management of civil infrastructure systems. Woodhead Publishing, pp 787-815

Publisher's Note Springer Nature remains neutral with regard to jurisdictional claims in published maps and institutional affiliations. 